This is the peer reviewed accepted manuscript of:

Raschi E, Mazzarella A, Antonazzo IC, Bendinelli N, Forcesi E, Tuccori M, Moretti U, Poluzzi E, De Ponti F.

Toxicities with Immune Checkpoint Inhibitors: Emerging Priorities From Disproportionality Analysis of the FDA Adverse Event Reporting System.

Target Oncol. 2019 Apr;14(2):205-221.

The final published version is available online at:

https://doi.org/10.1007/s11523-019-00632-w

Rights / License:

The terms and conditions for the reuse of this version of the manuscript are specified in the publishing policy. For all terms of use and more information see the publisher's website.

This item was downloaded from IRIS Università di Bologna (https://cris.unibo.it/)

When citing, please refer to the published version. 


\section{Toxicities with immune checkpoint inhibitors: emerging priorities from disproportionality analysis of the FDA Adverse Event Reporting System}

Running heading: Immune checkpoint inhibitors in the FDA Adverse Event Reporting System

Emanuel Raschi ${ }^{1}$, Alessandra Mazzarella ${ }^{1}$, Ippazio Cosimo Antonazzo ${ }^{1^{*}}$, Nicolò Bendinelli ${ }^{1^{*}}$, Emanuele Forcesi ${ }^{1}$, Marco Tuccori ${ }^{2}$, Ugo Moretti ${ }^{3}$, Elisabetta Poluzzi ${ }^{1}$, Fabrizio De Ponti ${ }^{1}$

${ }^{1}$ Pharmacology Unit, Department of Medical and Surgical Sciences, University of Bologna, Via Irnerio 48, 40126 Bologna, Italy

${ }^{2}$ Unit of Adverse Drug Reactions Monitoring, Tuscan Regional Centre of Pharmacovigilance, University Hospital of Pisa, Via Roma 55, 56126, Pisa, Italy

${ }^{3}$ Department of Public Health and Community Medicine, University of Verona, Verona, Italy

${ }^{*}$ equally contributed

Corresponding author:

Emanuel Raschi, MD, PhD

Alma Mater Studiorum - University of Bologna

Department of Medical and Surgical Sciences

Via Irnerio, 48 - 40126 Bologna BO Italy.

Tel: +39 - 051-20 91802. Fax: +39-051-2091780.

e-mail: emanuel.raschi@unibo.it

ORCID ID: 0000-0003-0487-7996

Word count: 4551

Number of tables: 4

Number of figures: 3

Number of references: 63

Supplementary material: 2 


\section{Abstract}

Background Different immune-related adverse events (irAEs) were described with immune checkpoint inhibitors (ICls), including blockers of cytotoxic T-lymphocyte associated protein 4 (CTLA4) and programmed cell death 1 or its ligand (PD1/PDL1), although their global safety is incompletely characterized.

Objective To characterize spectrum, frequency and clinical features of ICl-related adverse events (AEs) reported to the FDA Adverse Event Reporting System (FAERS).

Patients and Methods AEs from FAERS (up to June 2018) recording ICls (ipilimumab, nivolumab, pembrolizumab, atezolizumab, avelumab, durvalumab) as suspect were extracted. Comprehensive disproportionality analyses were performed through the reporting odds ratio (ROR) with $95 \%$ confidence interval $(95 \% \mathrm{Cl})$, using other oncological drugs as comparison. An overview of systematic reviews (OoSRs) was also undertaken to identify irAEs with consistent positive associations.

Results ICls were recorded in 47,266 reports, submitted mainly by consumers receiving monotherapy with anti-PD1/PDL1 drugs. Three areas of toxicity emerged from both disproportionality and OoSRs (33 studies): endocrine $(\mathrm{N}=2,863 ; \mathrm{ROR}=6.91 ; 95 \% \mathrm{Cl}=6.60-7.23)$, hepatobiliary $(2,632 ; 1.33 ; 1.28-1.39)$, respiratory disorders (7,240; 1.04; 1.01-1.06). Different reporting patterns emerged for anti-CTLA4 drugs (e.g., hypophysitis, adrenal insufficiency, hypopituitarism and prescribed overdose) and anti-PD1/PDL1 (e.g., pneumonitis, cholangitis, vanishing bile duct syndrome, tumour pseudoprogression and inappropriate schedule of drug administration). No increased reporting emerged when comparing combination with monotherapy regimen, but multiple hepatobiliary/endocrine/respiratory irAEs were recorded.

Conclusions This parallel approach through contemporary post-marketing analysis and OoSRs confirmed that ICls are associated with a multitude of irAEs, with different reporting pattern between anti-CTLA4 and anti-PD1/PDL1 medications. Close clinical monitoring is warranted to early diagnose and timely manage irAEs, especially respiratory, endocrine and hepatic toxicities, which warrant further characterization: patient- and drug-related risk factors should be assessed through analytical pharmaco-epidemiological studies and prospective multicenter registries. 


\section{Keypoints}

- As anticipated from pre-approval clinical trials, immune checkpoint inhibitors (ICls) are associated with large post-marketing reporting of variegate immune-related adverse events (irAEs), occurring virtually at any organ or tissue.

- Gastrointestinal disorders, hypophysitis and adrenal insufficiency were more frequently reported with anti-CTLA4 drugs, whereas thyroid dysfunction, pneumonitis, cholangitis, vanishing bile duct syndrome with anti-PD1/PDL1 agents.

- No increased reporting emerged when comparing combination with monotherapy regimen, but coreporting of hepatobiliary/endocrine/respiratory irAEs were recorded.

- This comprehensive analysis of the FDA Adverse Event Reporting System, together with a structured appraisal of published systematic reviews, identified endocrine, hepatic and respiratory toxicities as emerging safety priorities.

- These toxicities should be further characterized to verify the existence of a class effect (liver injury) and assess incidence and elucidate patient- and drug-related risk factors. 
Immunotherapy is changing the therapeutic landscape of several solid tumours. Immune checkpoint inhibitors (ICls) represent the cornerstone of these novel targeted approaches: they increase antitumor immunity through blockade of cytotoxic T-lymphocyte antigen 4 (CTLA4) and programmed cell death 1 (PD1) or its ligand (PDL1) [1, 2]. Ipilimumab, the first anti-CTLA-4 drug, caused a paradigm shift in drug development of these drugs: lessons learnt with its novel response kinetics and delayed separation of Kaplan-Meier survival curves led to change primary outcomes from response-based end points (overall response rate or progression-free survival) to overall survival [3].

From a safety standpoint, the increased activity of the immune system results in unique and distinct spectrum of side effects, the so-called immune-related adverse events (irAEs), which can affect different organs, especially gastrointestinal tract, endocrine glands, lung, and liver. Although irAEs are mild to moderate in severity and usually manageable [4], fulminant cases have been described [5], and the wide range of potential clinical manifestations requires multidisciplinary collaborative team, with several unresolved questions [6], including recommendations for mitigating and management of specific toxicities [7], and optimal algorithm for personalized shut-off treatment [8]. Pre-approval trials have shown better safety than chemotherapy, although combination of both CTLA4 and PD1 inhibitors (acting on distinct lymphocyte subtypes and at different sites) caused a higher incidence and a broader spectrum of irAEs [9].

Considering that $\mathrm{ICls}$ have entered clinical practice with great expectations, post-marketing monitoring is a crucial aspect to reach a well balanced view, and the term immuno-vigilance was recently coined [10]. Pivotal trials cannot fully assess rare AEs because of inconsistent reporting across trials [11], and case reports from the literature can only provide a partial epidemiological picture [12]. The analysis of international spontaneous reporting systems allows a broader view, by collecting unpublished reports of AEs submitted worldwide occurring in real-world unselected oncological patients with comorbidities and poly-pharmacotherapy, even in the long-term; this ensures rapid detection of even rare irAEs and emerging clinical entities such as myocarditis and coronary toxicity $[13,14]$, especially for biological/biotechnological medicinal products with peculiar pharmacokinetics-pharmacodynamics [15].

In this pharmacovigilance study, we analyzed AEs submitted to the US Adverse Event Reporting System (FAERS), in order to characterize their current safety profile (frequency, spectrum, clinical features), alone and in combination. Moreover, emerging toxicities were classified with relevant level of priority for further research, based on a structured literature appraisal. 


\section{Methods}

\subsection{Study concept and design}

The study was conceived as an observational, retrospective pharmacovigilance study combined with literature appraisal to identify (expected or previously-unknown) toxicities to be prioritized for further research (Figure 1). The former was designed as a disproportionality analysis based on unsolicited reports submitted to FAERS, whereas the latter was carried out as purposive literature search for systematic reviews of randomized controlled trials (RCTs), now referred to as overview of systematic reviews (OoSRs). This mixed approach compared two different real-world data (those from observational practice and those from RCTs) and would allow to: a) identify previously-unknown safety issues, 2) characterize known toxicities, 3) provide a public health perspective to recognized irAEs.

\subsubsection{FAERS: features, acquisition and processing}

FAERS is the US repository of AEs and medication errors spontaneously submitted by healthcare professionals, patients and manufacturers, gathering worldwide reports (including European reports potentially related to serious events and other non-US non- European data). In the recent past, FAERS and other spontaneous reporting systems were exploited in a number of post-marketing drug safety studies to assess both short- and long-term AEs for heterogeneous pharmacological classes [16], including biological products [17-20]. FAERS is particularly attracting among international pharmacovigilance databases because it covers a heterogeneous catchment area (allowing broader generalization of findings) and offers public access to raw data that can be downloaded in a format suitable for customized analyses [21]. Moreover, previous studies have demonstrated great accuracy in early detection of safety issues, especially for newly-approved drugs (i.e., on the market since no more than 5 years) [22], as well as to monitoring AEs with low/rare background incidence [23].

Publicly released version of FAERS was downloaded from relevant website [from the first quarter (Q1) of 2004 through Q2 of 2018]. Before performing customized statistical analyses, FAERS was processed for data quality, including removal of duplicates (i.e., reports with overlaps in 3 out of 4 key fields, namely event date, age, gender and Reporter Country), and standardization of drug names into relevant active substances [24]. AEs can be analyzed through the standardized Medical Dictionary for Regulatory Activities (MedDRA) terminology (version 19); in FAERS, they are coded in terms of Preferred Terms (PTs), which identified specific signs/symptoms of a given clinical entity; the hierarchical structure of MedDRA allows grouping PTs (high specificity) into relevant System Organ Class (SOC, high sensitivity). 


\subsubsection{Disproportionality analysis}

Disproportionality analysis is a validated concept in pharmacovigilance that compares the proportion of selected AEs reported for a single drug or drug class (e.g., ICls) with the proportion of the same AEs for a control group of drugs (e.g., other anticancer agents). The denominator in these analyses is the total number of reports of AEs for each group of drugs. If the proportion of AEs is greater in patients exposed to a specific drug (cases) than in patients not exposed to this drug (non-cases), an association can be hypothesized between the specific drug and the event. Through this so-called case/non-case approach, which can be viewed as a case-control analysis, the reporting odds ratio (ROR) with relevant $95 \%$ confidence interval $(95 \% \mathrm{Cl})$ was calculated. Disproportionality was considered statistically significant when the lower limit of the $95 \% \mathrm{Cl}$ of the ROR exceeds 1 , as recommended [24, 25]. Exposure assessment considered ICls (ipilimumab, nivolumab, pembrolizumab, atezolizumab, avelumab, durvalumab approved as of June 2018) recorded as "primary suspect" or "secondary suspect". Therefore, active substances and brandnames represented our criteria to select reports relevant to ICls.

Pharmacovigilance in oncology is not straightforward, as compared to other medical areas. Frequent use of multiple therapeutic regimens makes it difficult to disentangle side effects of individual drugs versus drug-drug interactions versus "innocent bystander" effects [26]. Moreover, complexity of patient histories results in high potential for confounding and effect modification (i.e., drug-disease interactions). Finally, the unique benefit-risk consideration may result in a higher threshold for recognizing and reporting AEs. Therefore, different data-mining steps were specifically performed to refine disproportionality analysis and minimize biases as follows: (a) to reduce the likelihood of false positives, disproportionality was calculated only when at least five cases of interest were reported, instead of the traditional signaling criterion of three cases [27]; (b) to provide a clinical perspective, the so-called analysis by therapeutic area (main analysis) was adopted by comparing ICls versus other oncological drugs (using AEs recording at least one anticancer agent) [28]; (c) to minimize the existence of an "indication bias" (i.e., the indication for which the drugs is prescribed is reported as an AE), reports with overlap between therapeutic indication and reported AE were removed a priori from the whole FAERS database (e.g., melanoma reported as $\mathrm{AE}$ in patients receiving nivolumab for melanoma).

Analyses were first performed at the SOC level to describe the spectrum of toxicities. Subsequently, key toxicities emerging form the combined assessment with the literature were characterized in terms of specific signs/symptoms (PT level), and ICI regimens (anti-CTLA4 and anti-PD1/PDL1, monotherapy vs combination therapy). Additional analyses were also performed to test the consistency of results by considering only data after April 2011 (i.e., considering the affective period on the market of ICls with the approval of the first-in-class ipilimumab on March $23^{\text {rd }}, 2011$ ); and comparing $\mathrm{ICls}$ with monoclonal 
antibodies (considering the biotechnological nature of these drugs and pharmacological similarities).

\subsection{Literature selection and appraisal}

The OoSRs was conducted in MEDLINE (via Pubmed, on 29/10/2018) to find SRs of RCTs on the safety of $\mathrm{ICl}$, with restriction to the English articles published up to June 2018. Detailed criteria for article retrieval (search strategy) and eligibility are provided as supplementary material_(Supplementary Material 1).

This OoSRs adopts an "evidence summary" approach. First, potentially-eligible SRs were assessed for quality by applying the validated AMSTAR tool [29]. Second, SRs were assessed for actual eligibility as follows: only direct comparisons between ICls (as a class or as a single drug) and chemotherapy were selected (indirect network meta-analyses were excluded); meta-analysis without SRs (e.g., pooled analysis) or meta-analysis on the overall safety without specifying/separating AEs in terms of affected organ/system (e.g., fatal irAEs) were excluded. Third, risk estimates were extracted for the various safety outcomes, and used to assess study results. If statistically-significant odds ratio/hazard ratio was found, the study was deemed as "positive", namely it demonstrated an increased occurrence/risk of a given AE with ICls; "negative" studies were those with statistically-significant reduced occurrence/risk with ICls; "neutral" studies were defined when there was no evidence of significant difference (ICls as effective/safe as comparator) or uncertainty/inconclusive data (e.g., high heterogeneity or inconsistencies across sensitivity analyses). SRs reporting only incidence rates were not evaluated, whereas SRs investigating multiple AEs counted as many-fold as the number of outcomes investigated. In case of multiple analyses, data on grade 3-4 severity were preferred.

Because multiple SRs were identified on the same topic, the totality of SRs was evaluated for robustness (consistency of the findings among SRs in relation to the number of published studies). The following assessment was finally adopted:

CONSISTENT POSITIVE ASSOCIATION= more than a half of SRs were concordant in documenting an increased occurrence with ICls;

CONSISTENT NEGATIVE ASSOCIATION= more than a half of SRs were concordant in documenting a reduced occurrence with ICls;

NEUTRAL ASSOCIATION= more than a half of SRs were concordant in documenting no evidence of risk .

UNCERTAIN ASSOCIATION= a single SR was available, or conflicting results from two or more SRs. 
Data from literature appraisal and disproportionality analysis were compared for consistency of findings, and four levels of priority were assigned to the different toxicities:

A) TOP PRIORITY: toxicity emerging from disproportionality, with consistent positive association from the OoSRs (i.e., concordance between pre-approval and post-marketing evidence).

B) HIGH PRIORITY: toxicity emerging from disproportionality without data from OsSRs (i.e., only evidence from post-marketing data).

C) INTERMEDIATE PRIORITY: toxicity without disproportionality but consistent positive association from the OsSRs (i.e., only evidence from pre-approval data)

D) LOW PRIORITY: toxicity without disproportionality and neutral/uncertain association from OsSRs.

As anticipated, top and high priorities were further characterized through additional disproportionality analyses in terms of specific signs/symptoms and ICI regimens.

\section{Results}

\subsection{Descriptive analysis of FAERS and literature appraisal}

Over the 15-year period, 16,331,098 FAERS reports were initially processed for drug codification, duplicate removal and aforementioned quality criteria; 8,922,294 reports were finally retained, of which $47,266(0.53 \%)$ included at least one ICI (Figure 1). The highest number of reports emerged for nivolumab $(N=24,560)$ followed by ipilimumab $(N=13,971)$ and pembrolizumab $(N=10,425)$. The reported Country was US in 57\% of reports. Young adults and subjects aged $>65$ years old were similarly represented (30-33\%), with slight male preponderance (53\%, with very similar proportion across various medications) (Table 1). The majority of reports were serious (>80\%), namely resulting in hospitalization (30\%), death (29\%) or lifethreatening events (3\%). A peak in reporting of death was noted for atezolizumab (50\%). Notably, consumers were the main source of reports ( $34 \%$, peaking $79 \%$ for atezolizumab), followed by other healthcare professionals and clinicians (30\% each). Over years, there was an exponential increase in the number of submitted reports, especially for monotherapy regimen with anti-PD1/PDL1 drugs, with two remarkable peaks in the first quarter of 2017 and second quarter of 2018 (Figure 2). General disorders and administration site conditions was the SOC with the highest number of reports $(16,449)$, followed by gastrointestinal disorders $(9,124)$ and neoplasms benign. malignant and unspecified (incl cysts and polyps) $(8,773)$.

The literature search yielded 1,539 studies, which were screened based on aforementioned exclusion criteria: 50 SRs were retained and evaluated for quality, of which 32 were used for quantitative 
assessment (Figure 1). The overall quality according to the AMSTAR tool was judge high ( $\geq 9)$ for 25 SRs

(Supplementary Material 1). Skin (13 studies), gastrointestinal (11), respiratory (10 studies), hepatobiliary (9) and endocrine disorders (8) were the most frequently investigated toxicities. Consistent positive associations finally emerged for endocrine, hepatobiliary, gastrointestinal, skin and respiratory disorders, whereas blood/lymphatic system disorders and general disorders and administration site conditions were deemed to be consistent negative associations.

\subsection{Disproportionality analysis of FAERS}

The disproportionality analysis highlighted six areas of toxicity with statistically significant ROR: endocrine disorders $(\mathrm{N}=2,863 ; \mathrm{ROR}=6.91 ; 95 \% \mathrm{Cl}=6.60-7.23)$, hepatobiliary disorders $(2,632 ; 1.33 ; 1.28$ 1.39), injury. poisoning and procedural complications $(6,776 ; 1.20 ; 1.17-1.23)$, neoplasms benign, malignant and unspecified (incl cysts and polyps) $(8,773 ; 1.85 ; 1.81-1.90)$, respiratory. thoracic and mediastinal disorders $(7,240 ; 1.04 ; 1.01-1.06)$, surgical and medical procedures $(1,298 ; 1.20 ; 1.13-1.27)$ (Table 2).

Results were consistent across sensitivity analyses. Specifically, the ROR remained statistically significant when ICls were compared with monoclonal antibodies, with the exception of respiratory, thoracic and mediastinal disorders $\quad(\mathrm{ROR}=0.92 ; 95 \% \mathrm{Cl}=0.90-0.95)$; likewise, no major changes to the RORs emerged when the analyses were restricted to the 2011Q2-2018Q2 period, with the exception of metabolism and nutrition disorders that reached the threshold for statistical significance $(1.13 ; 1.10-1.17)$. No disproportionate reporting was found when confronting monotherapy versus combination regimens, whereas a different reporting frequency (i.e., statistically significant ROR) emerged when anti-CTLA4 agents were compared with anti-PD1/PDL1 medications for different toxicities, including endocrine disorders (1.60; 1.46-1.75), eye disorders (1.21; 1.05-1.39), gastrointestinal disorders (2.03; 1.93-2.15), metabolism and nutrition (1.15; 1.06-1.25), pregnancy, puerperium and perinatal conditions (2.28; 1.07-4.86), skin and subcutaneous tissue disorders $(1.28 ; 1.19-1.37)$.

\subsection{Characterization of emerging toxicities}

The combined analysis of FAERS data with literature appraisal highlighted endocrine, hepatobiliary and respiratory disorders as top priorities, whereas injury, poisoning and procedural complications, neoplasm (benign, malignant and unspecified) disorders, and surgical/medical procedures emerged as high priorities (Table 3 ). The most frequently reported AEs with disproportionality for all ICls were 
hypothyroidism ( $\mathrm{N}=777 ; \mathrm{ROR}=6.36 ; 95 \% \mathrm{Cl}=5.85-6.93)$, hypophysitis $(594 ; 20.8 ; 11.13-38.86)$, and adrenal insufficiency $(493 ; 10.03 ;$ 8.88-11.33) for endocrine events, with higher reporting with anti-CTLA4 agents; conversely, thyroid dysfunctions were more frequent with anti-PD1/PDL1 drugs. The ranking was hepatitis (420; 3.12; 2.81-3.47), hepatic function abnormal (385; 1.55; 1.39-1.72), and autoimmune hepatitis (373; 14.23; 11.90-17.00) for liver injuries, with higher reporting for cholangitis with antiPD1/PDL1 medicines (106; $2.51 ; 2.05-3.07)$. For respiratory toxicities, disproportionality was found for pneumonitis $(1,289 ; 4.06$; 3.82-4.32) and interstitial lung disease (794; 1.63; 1.52-1.75), with higher reporting frequency for antiPD1/PDL1 drugs (Table 4). Frequency of co-reporting among endocrine, hepatobiliary and respiratory disorders are presented in Figure $\mathbf{2}$.

Among toxicities receiving high priority the most frequently reported AEs were: malignant neoplasm progression $(6,691 ; 5.94 ; 5.77-6.12)$, product use in unapproved indication $(1,734 ; 6.29$; 5.94 6.66) and transfusion (172; 5.19; 4.37-6.16). Different reporting frequencies were observed for tumour pseudoprogression and inappropriate schedule of drug administration with anti-PD1/PDL1 drugs, and prescribed overdose for anti-CTLA4 agents. The full list of AEs (top and high priorities) with relevant disproportionality is provided in Supplementary Material 2.

\section{Discussion}

To our knowledge, this is the largest comprehensive analysis of post-marketing AEs attributed to ICls collected from a worldwide pharmacovigilance database: apart from recently-approved avelumab and durvalumab, there is considerable amount of data for nivolumab, ipilimumab, alone and in combination, and pembrolizumab.

Overall, four main findings emerged. First, the exponential increase in the number of AEs, especially since 2017, is noteworthy (ICls account for $4.8 \%$ of total reports with anticancer drugs collected over 13 years) and may be ascribable to various reasons, including the perceived expectations on this immunotherapy that reduced the phenomenon of "clinical inertia" usually observed for non-anticancer drugs, and the progress extension of therapeutic indications in different oncological settings for antiPD1/PDL1 agents, as well as the case of agnostic approval for pembrolizumab.

Second, the spectrum of irAEs is variegate and, virtually, any organ of tissue can be involved: endocrine systems, liver, lung, gastrointestinal tract and skin, among others, thus emphasizing the importance of timely identification and early personalized management through multidisciplinary tumour board $[7,8]$. Notably, Individuals receiving ICls may experience a unique set of AEs in comparison with firstand second-generation anticancer agents, including monoclonal antibodies: "traditional" biologics are associated with high frequency of reports related to general disorders/administration site condition (owing 
to the parenteral administration) and predictable toxicities such as infections and neoplasm due to an or not these irAEs are actually predictable. According to RCTs, ipilimumab exhibits a clear dose-dependent relationship with regards to incidence and severity of irAEs, although the mechanistic basis of toxicity may vary depending on the damaged organ [30].

Third, different reporting frequencies were observed between anti-CTLA4 drugs and anti-PD1/PDL1 agents: gastrointestinal disorders, endocrine and skin disorders were more frequently reported with antiCTLA4 drugs (ipilimumab), especially hypophysitis adrenal insufficiency, hypopituitarism and prescribed overdose, whereas thyroid dysfunction, pneumonitis, cholangitis, tumour pseudoprogression and inappropriate schedule of drug administration with anti-PD1/PDL1 agents. Similar frequencies were reported for autoimmune hepatitis and malignant neoplasm progression. These figures are strongly in agreement with the evidence from previous studies, including SRs of RCTs [11, 31, 32] and other pharmacovigilance analyses [33-35], thus confirming a close correlation between relative risks/hazard ratios and disproportionality measures in the modern FAERS [36]. Although the reasons of the observed reporting pattern remain obscure (and only partially reside on the different mechanisms of action), these differences in observed toxicities should be carefully considered by clinicians during monitoring to early intercept serious irAEs and timely optimize treatment strategy.

Fourth, we obtained some unique findings, including: A) no increased reporting with combination regimen, which is likely to be related to the remarkable reporting frequency of anti-PD1/PDL1 monoclonal antibodies; B) overlap in co-reporting of endocrine, hepatobiliary and respiratory irAEs, which carries important implications in clinical monitoring. Based on pre-approval clinical trials data, most of these irAEs observed with ICls (especially ipilimumab) typically follow a chronological pattern; they start within the first 8-12 weeks from treatment, with endocrine gland affection usually appearing later at around 9 weeks [37]. Therefore, regular monitoring is required to early assess and manage these toxicities while avoiding therapy interruption; C) higher reporting of cholangitis and vanishing bile duct syndrome with antiPD1/PDL1 monoclonal antibodies. Drug-induced liver injury with ICls represents an emerging area of research [38]; recent data from a pharmacovigilance register in France characterized 536 patients with grade 3 hepatitis and highlighted the importance of liver biopsy to patient-guided approach to avoid corticosteroids [39]. While previous data suggested that ipilimumab may be associated with higher liver toxicity rates, as compared to ICls blocking PD-1 [40], our findings support the existence of a specific pattern of liver damage for the different ICls. In fact, while a signal of autoimmune hepatitis consistently emerged for all checkpoint inhibitors, an increased reporting of cholangitis was found for anti-CTLA4 drugs (nivolumab), in line with recent case series [41-45]. This form of severe and prolonged liver toxicity can manifest as "large-ducts or small-ducts cholangitis", and may have different clinical presentation, 
biochemical evolution and outcome, including secondary sclerosing cholangitis [46]. The occurrence of

immune-related cholangitis has been described in subject receiving nivolumab and avelumab, with late onset not only after administration of the treatment, but also after discontinuation of nivolumab [47]. Notably, we also found in FAERS 6 cases of vanishing bile duct syndrome with statistically-significant disproportionality ( $\mathrm{ROR}=3.51 ; 95 \% \mathrm{Cl}=1.48-8.31$; supplementary material 2 ). To our knowledge, this is the first documentation of this pattern of liver injury with ICls [48]. Taken together, this collated body of evidence call for analytical pharmaco-epidemiological research to assess the risk at the population level and multicenter prospective registries to define the optimal treatment strategy in the individual patient and elucidate risk factors.

Disproportionalities found in our study for medical/surgical procedures, injury/poisoning/procedural complications, and neoplasms received a high priority, as they appear to be previously-unknown safety aspects. The first area of toxicity can be interpreted as underlying cancerrelated complications rather than specific drug-related issues, whereas the second area of toxicity is mainly related to aspects dealing with drug administration (over- and under-dose, use in unapproved indications, schedule of administration) and may be a potential consequence of the recent European pharmacovigilance legislation, which modified the definition of adverse drug reaction, by including also issues related to quality aspects, lack of efficacy and "non-normal use" (i.e., abuse, misuse, overdose, occupational exposure, and medication errors) of medicines. We can therefore hypothesize that this regulatory context might result in increased awareness by clinicians on the importance of submitting AEs, thus creating a new type of notoriety bias.

Conversely, different clinical reasons may explain the high reporting of AEs potentially suggestive of "drug ineffective" (i.e., malignant recurrence): 1) the aforementioned notoriety bias. This hypothesis is supported by recent data highlighting that "drug ineffective" as the most commonly reported AE in FAERS [49]. Additional studies performed on WHO-Vigibase data indicated that clusters of substandard medicines can be identified via specific algorithm, although under stringent key prerequisites [50, 51]. Patients' reporting in social media may complement information from clinicians to describe quality issues and impact on quality of life [52]; 2) the atypical delayed therapeutic response with $\mathrm{ICls}$, as compared with other targeted anticancer drugs; 3 ) the recently-described phenomenon of "pseudoprogression" (or even an aggressive pattern of hyperprogression [53]), a distinct immune-related pattern of response, caused by the infiltration of immune cells to the tumor site that can manifest in the form of an apparent relapse (e.g., increase in tumor size, the development of new lesions [54]). Therefore, occurrence of irAEs in early phase of therapy, including the aforementioned pseudoprogression, without apparent clinical benefit might discourage clinicians in pursuing $\mathrm{ICl}$ treatment while reporting a potential lack of efficacy. Oncologist should be reminded that therapeutic effect occurs later as compared to the onset of irAEs, and that current data 
support positive association between these immunological events and survival outcome, as documented for nivolumab in non-small-cell lung cancer [55-57].

Among toxicities with intermediate priority, gastrointestinal and skin disorders warrant brief discussion. Our data indicated that these safety issues have a non-negligible reporting, but did not result in significant disproportionality. Clinicians should be reminded that these toxicities do occur and may be even fatal, especially colitis: initial assessment is crucial when starting ICI treatment, since early management might prevent progression to more severe toxicity [37].

\subsection{Strengths and limitations}

We exploited different data sources for safety assessment, including an OoSRs and a contemporary disproportionality analysis of the largest open-source worldwide database of unsolicited reports. To the best of our knowledge, only one integrated approach was recently carried out to assess ICI safety, although it was specifically focused on fatal toxic effects, thus making actual characterization and generalizability challenging [34].

We provided the most updated and comprehensive characterization of irAEs, and further raised debate on whether or not analysis of spontaneous reporting system can be used to highlight clinical importance of toxic effects or suggest foci of potential drug misuse, unconventional uses and, most intriguingly, lack of efficacy. Although RCTs remain the best experimental approach to actually inform on the efficacy of medications, our study provided the public health perspective of toxicities receiving attention and largely investigated in the recent past, with consistent data: hepatic, endocrine and respiratory irAEs warrant further prospective assessment to quantify and evaluate actual risk (class effect versus individual drug), including strategies for optimal management.

The vast amount of SRs on irAEs (i.e., multiple reviews on the same topic) is a double-edge sword: on one hand, this prompted us to verify consistency of findings; on the other hand, it challenged decisionmaking process of both clinicians and regulators. Our critical appraisal calls for the need to move from systematic reanalysis of the existent literature towards a new era of evidence-based medicine through comparative effectiveness/safety research and combination of multiple sources of real-world data.

We acknowledge limitations of FAERS data, in particular the inability to infirm causal relationship between drug exposure and occurrence of AE [21]. The ROR does not inform on the real risk in clinical practice, mainly because of lack of denominator and under-reporting, but only indicates an increased risk of $A E$ reporting and not a risk of $A E$ occurrence. Therefore, incidence rates and risk ranking cannot be inferred from spontaneous reports. These aspects are shared by all pharmacovigilance databases and causal inferences is also an inherent limitation of cohort studies. We cannot exclude the so-called channeling bias 
(i.e., the possibility that drugs may be differently prescribed in relation to the severity of disease). In fact, clinical information such as cancer severity and duration is lacking, as well as laboratory and radiological findings and incomplete reporting of dosing, time to onset, thus making a firm comparison among ICls inappropriate [58]. We also recognized that residual confounders may exist, including synergy with comorbidities and co-medications resulting in potential drug-drug interactions [59], although a number of measures were planned to minimize biases. We also acknowledge that both false-positive and falsenegative results might exist. We cannot exclude that some AEs such as metastasis do not represent an indication bias considering that ICls are also indicated in metastatic settings. Conversely, some AEs might not be identified because of their rarity or due to methodological issues: disproportionality measures are interdependent and the literature assessment was not intended to be a systematic review but an OoSRs of RCTs; this may explain the reason why cardiovascular toxicity did not emerge as top priority [60].

Notwithstanding these limitations, pharmacovigilance assessment represents an invaluable opportunity to monitor drug safety and identify new rare signals. We have described the worldwide safety profile of ICls in an unselected population; major confounders were accounted for, by applying multiple "quality criteria" to minimize the likelihood of false positives and other sources of bias (e.g., selection of 5 cases as threshold for calculating disproportionality, removal of reports suggestive of potential indication bias). There are no reasons to support the existence of stimulated reporting/notoriety bias specifically referring to a given AE (regulatory warnings are largely homogeneous across pharmacological classes), and the Weber effect (i.e., a peak in reporting early after approval and a decline hereinafter) was not demonstrated for oncological drugs, and do not emerged from our data [61].

Taken together, our findings and the overall body of the evidence call for proactive immunevigilance and should stimulate the conduction of post-authorization studies, as recommended by the European Medicines Agency, to define the magnitude and extent of irAEs and actual clinical effectiveness, especially in the metastatic setting. In particular, the oncological area should move beyond adaptive designs and pragmatic clinical trials to embrace new avenues of Big Smart data [62], such as combining population-based registries with health record systems [63]. 


\section{Conclusions}

Notwithstanding limitations, these real-world FAERS data corroborated the usefulness of pharmacovigilance research and confirmed that irAEs with ICls may virtually occur at any organ/tissue, including co-occurrences, with different reporting frequencies between anti-CTLA4 drugs (hypophysitis, adrenal insufficiency) and anti-PD1/PDL1 agents (thyroid dysfunction, pneumonitis, cholangitis, vanishing bile duct syndrome).

These findings strengthened the importance of: A) close clinical monitoring of patients to early diagnose and timely manage irAEs, awaiting for the delayed therapeutic response; B) proactive multidisciplinary pharmacovigilance to maintain "real-time" surveillance (especially for recently-approved $\mathrm{ICls}$ such as avelumab, durvalumab, and considering emerging combination regimens with other oncological agents); C) prioritize respiratory, endocrine and liver toxicities to assess and further characterize patient- and drug-related risk factors through analytical pharmaco-epidemiological research and multicenter registries.

\section{Compliance with Ethical Standards}

\section{Funding}

No sources of funding were used to assist in the preparation of this study. Authors at the University of Bologna (ER, EP, FDP) are supported by Institutional Research Funds (Ricerca Fondamentale Orientata).

\section{Conflict of Interest}

Authors declare no potential conflict of interest relevant to the content of the manuscript. 


\section{Figure Captions}

Fig. 1. Flow Chart to compare FAERS analysis with Literature assessment. ICl: immune checkpoint inhibitor; SRs: systematic reviews.

* Primary Suspect or Secondary Suspect (see text for details). RCTs: randomized controlled trials.

Fig. 2. Time trends of spontaneous reports collected for $\mathrm{ICls}$, according to the therapeutic regimen. Approval dates and therapeutic indications are also presented, according to the Food and Drug Administration. NSCLC: non-small cell lung cancer

Fig. 3. Overlap among AEs reported for endocrine, hepatobiliary and respiratory disorders.

\section{Supplementary Material 1}

Details on literature evaluation: search strategy (with inclusion/exclusion criteria), quality assessment of retained systematic reviews according to the AMSTAR tool, and data extracted from individual systematic reviews.

\section{Supplementary Material 2}

Disproportionality analysis at the Preferred Term level of the four SOCs emerging with statisticallysignificant ROR in the main analysis and receiving top and high priority based on a parallel literature appraisal. 
Table 1. Demographic data. In parentheses relevant percentage is provided (out of total reports). The sum of the number of cases for the different ICls may be higher than the total number of cases for the drug class because a patient may have received more than one drug (combination regimen).

\begin{tabular}{|c|c|c|c|c|c|c|c|c|c|}
\hline & & & $\mathrm{ICl}$ as a class & Nivolumab & Ipilimumab & Pembrolizumab & Atezolizumab & Avelumab & Durvalumab \\
\hline \multicolumn{3}{|l|}{ Total Reports } & 47,266 (\%) & $24,560(\%)$ & $13,971(\%)$ & $10,425(\%)$ & 2,663 (\%) & $383(\%)$ & $405(\%)$ \\
\hline \multirow{5}{*}{$\begin{array}{l}\text { Geographical } \\
\text { distribution }\end{array}$} & EU & & $11,437(24.20)$ & $6,718(27.35)$ & $3,270(23.41)$ & $1,816(17.42)$ & 896 (33.65) & $145(37.86)$ & $149(36.79)$ \\
\hline & \multirow{4}{*}{ Non EU } & Africa & $83(0.18)$ & $50(0.2)$ & $13(0.09)$ & $19(0.18)$ & $4(0.15)$ & & \\
\hline & & Americas & $27,134(57.41)$ & $12,974(52.83)$ & $9,363(67.02)$ & $6,058(58.11)$ & 1,286 (48.29) & $143(37.34)$ & $228(56.3)$ \\
\hline & & Asia & 7,298 (15.44) & 4,150 (16.9) & 876 (6.27) & 2,197 (21.07) & 424 (15.92) & $72(18.8)$ & $20(4.94)$ \\
\hline & & Oceania & $1,253(2.65)$ & $636(2.59)$ & $419(3)$ & $327(3.14)$ & $52(1.95)$ & $23(6.01)$ & 7 (1.73) \\
\hline \multirow{4}{*}{$\begin{array}{l}\text { Age group } \\
\text { distribution }\end{array}$} & $0-17$ & & $118(0.25)$ & $73(0.3)$ & $31(0.22)$ & $21(0.2)$ & $6(0.23)$ & & \\
\hline & $18-64$ & & 14,261 (30.17) & $7,089(28.86)$ & $5,046(36.12)$ & $2,968(28.47)$ & $1,052(39.5)$ & $171(44.65)$ & $135(33.33)$ \\
\hline & $>65$ & & 15,489 (32.77) & 7,801 (31.76) & $4,013(28.72)$ & $3,980(38.18)$ & $1,029(38.64)$ & $168(43.86)$ & $166(40.99)$ \\
\hline & UKW & & $17,401(36.82)$ & $9,597(39.08)$ & $4,881(34.94)$ & 3,456 (33.15) & $576(21.63)$ & 44 (11.49) & $104(25.68)$ \\
\hline \multirow{3}{*}{$\begin{array}{l}\text { Patient sex } \\
\text { distribution }\end{array}$} & $M$ & & $25,247(53.41)$ & $13,062(53.18)$ & 7,561 (54.12) & $5,629(54.00)$ & $1,425(53.51)$ & $205(53.52)$ & $218(53.83)$ \\
\hline & $F$ & & $15,329(32.43)$ & 7,605 (30.96) & 4,481 (32.07) & $3,699(35.48)$ & $1,002(37.63)$ & $158(41.25)$ & $151(37.28)$ \\
\hline & UKW & & 6,694 (14.16) & $3,893(15.85)$ & $1,929(13.81)$ & $1,097(10.52)$ & $236(8.86)$ & $20(5.22)$ & $36(8.89)$ \\
\hline \multirow{6}{*}{$\begin{array}{l}\text { Outcome } \\
\text { distribution\# }\end{array}$} & $\mathrm{HO}$ & & 14,034 (29.69) & 7,096 (28.89) & $5,204(37.25)$ & $2,567(24.62)$ & 1,335 (50.13) & $226(59.01)$ & $188(46.42)$ \\
\hline & $\mathrm{DE}$ & & 13,787 (29.17) & $8,068(32.85)$ & $3,014(21.57)$ & $3,160(30.31)$ & 521 (19.56) & $87(22.72)$ & $64(15.8)$ \\
\hline & OT & & $10,560(22.34)$ & $5,861(23.86)$ & $3,032(21.7)$ & $2,138(20.51)$ & $343(12.88)$ & $30(7.83)$ & $63(15.56)$ \\
\hline & LT & & $1,632(3.45)$ & $839(3.42)$ & $423(3.03)$ & 426 (4.09) & $130(4.88)$ & $21(5.48)$ & $17(4.2)$ \\
\hline & DS & & $287(0.61)$ & $123(0.5)$ & $51(0.37)$ & $108(1.04)$ & $14(0.53)$ & $1(0.26)$ & $2(0.49)$ \\
\hline & CA & & $3(0.01)$ & & $1(0.01)$ & $2(0.02)$ & & & \\
\hline
\end{tabular}




\begin{tabular}{|c|c|c|c|c|c|c|c|c|}
\hline & UKW & 6,966 (14.74) & $2,573(10.48)$ & $2,246(16.08)$ & $2,024(19.41)$ & $320(12.02)$ & $18(4.7)$ & $71(17.53)$ \\
\hline \multirow{6}{*}{$\begin{array}{l}\text { Reporter's } \\
\text { occupation } \\
\text { distribution }\end{array}$} & $\mathrm{CN}$ & $16,292(34.47)$ & 6,919 (28.17) & 5,085 (36.4) & $5,141(49.31)$ & 167 (6.27) & $10(2.61)$ & 21 (5.19) \\
\hline & OT & $14,241(30.13)$ & $9,344(38.05)$ & $5,750(41.16)$ & $1,736(16.65)$ & $260(9.76)$ & $90(23.5)$ & $90(22.22)$ \\
\hline & MD & $14,231(30.11)$ & 6,855 (27.91) & $2,617(18.73)$ & $3,049(29.25)$ & $2,108(79.16)$ & $277(72.32)$ & $260(64.2)$ \\
\hline & $\mathrm{PH}$ & $2,284(4.83)$ & $1,359(5.53)$ & $453(3.24)$ & $441(4.23)$ & 119 (4.47) & $6(1.57)$ & $15(3.7)$ \\
\hline & LW & $14(0.03)$ & $10(0.04)$ & & $4(0.04)$ & & & \\
\hline & UKW & $210(0.44)$ & $73(0.3)$ & $66(0.47)$ & $54(0.52)$ & $9(0.34)$ & (0) & $19(4.69)$ \\
\hline \multirow{2}{*}{$\begin{array}{l}\text { Therapeutic } \\
\text { regimen }\end{array}$} & Monotherapy & $42,156(89,19)$ & $19,606(79,83)$ & $8,903(63,72)$ & $10,209(97,93)$ & $2,652(99,59)$ & $382(99,74)$ & $404(99,75)$ \\
\hline & Combination & $5,110(10,81)$ & $4,954(20,17)$ & $5,068(36,28)$ & $216(2,07)$ & $11(0,41)$ & $1(0,26)$ & $1(0,25)$ \\
\hline \multirow{9}{*}{ Reporting year } & Before 2011 & $68(0,14)$ & & $68(0,49)$ & & & & \\
\hline & 2011 & $652(1,38)$ & $1(0)$ & $652(4,67)$ & & & & \\
\hline & 2012 & $1,189(2,52)$ & $5(0,02)$ & $1,187(8,5)$ & & & & \\
\hline & 2013 & $1,080(2,28)$ & $26(0,11)$ & $1,073(7,68)$ & & & & \\
\hline & 2014 & $2,046(4,33)$ & $119(0,48)$ & $1,646(11,78)$ & $393(3,77)$ & $3(0,11)$ & & \\
\hline & 2015 & $5,157(10,91)$ & $2,462(10,02)$ & $2,111(15,11)$ & $1,295(12,42)$ & $20(0,75)$ & & \\
\hline & 2016 & $10,989(23,25)$ & $7,037(28,65)$ & $2,079(14,88)$ & $2,290(21,97)$ & $553(20,77)$ & $6(1,57)$ & $14(3,46)$ \\
\hline & 2017 & $15,769(33,36)$ & $9,098(37,04)$ & $3,245(23,23)$ & $3,777(36,23)$ & $1,158(43,48)$ & $186(48,56)$ & $136(33,58)$ \\
\hline & $2018^{*}$ & $10,316(21,83)$ & $5,812(23,66)$ & $1,910(13,67)$ & $2,670(25,61)$ & $929(34,89)$ & $191(49,87)$ & $255(62,96)$ \\
\hline
\end{tabular}

EU: European Union; UKW: unknown (missing data); F: females; M: males; CA: congenital anomaly; DE: death; DS: disability; HO: hospitalization (initial or prolonged); LT: lifethreatening; OT (outcome distribution): other serious (important medical event); OT (reporter's occupation distribution): other health-professional; MD: medical doctor; PH: pharmacist; LW: lawyer; CN: consumer.

* Up to Q2 (June 2018)

\# because different degrees of seriousness may be recorded in a single report, the final level of seriousness was assigned based on the following ranking: death>lifethreatening>hospitalization>disability>congenital anomaly>other serious. 


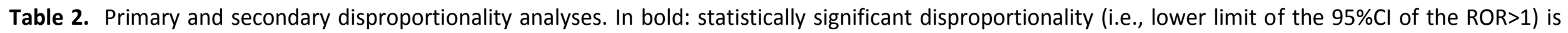
shown with a dark background.

\begin{tabular}{|c|c|c|c|c|c|c|c|c|c|c|}
\hline \multirow[b]{2}{*}{ Toxicity of interest } & \multicolumn{2}{|c|}{$\begin{array}{c}\text { ICI vs other anticancer } \\
\text { drugs } \\
\text { (Q2/2004-Q2/2018) }\end{array}$} & \multicolumn{2}{|c|}{$\begin{array}{c}\text { ICls vs other anticancer } \\
\text { drugs } \\
\text { (Q2/2011-Q2/2018) }\end{array}$} & \multicolumn{2}{|c|}{$\begin{array}{l}\text { ICls vs monoclonal } \\
\text { antibodies } \\
\text { (Q2/2004-Q2/2018) }\end{array}$} & \multicolumn{2}{|c|}{$\begin{array}{c}\text { monotherapy vs } \\
\text { combination } \\
(n=42,156)\end{array}$} & \multicolumn{2}{|c|}{$\begin{array}{c}\text { Anti-CTLA4 } \\
\text { monotherapy vs anti- } \\
\text { PD1/PDL1 monotherapy } \\
(n=8,903)\end{array}$} \\
\hline & $\mathbf{N}$ & ROR (95\%Cl) & $\mathbf{N}$ & ROR (95\%Cl) & $\mathbf{N}$ & ROR (95\%Cl) & $\mathbf{N}$ & ROR (95\%Cl) & $\mathbf{N}$ & ROR (95\%Cl) \\
\hline $\begin{array}{l}\text { Blood and lymphatic system } \\
\text { disorders }\end{array}$ & 3,134 & $0.48(0.47-0.50)$ & 3,125 & $0.54(0.52-0.56)$ & 3,134 & $0.46(0.44-0.48)$ & 2,780 & 0.99 (0.89-1.11) & 513 & $0.87(0.78-0.96)$ \\
\hline Cardiac disorders & 2,589 & $0.67(0.64-0.70)$ & 2,583 & $0.85(0.81-0.88)$ & 2,589 & $0.67(0.64-0.70)$ & 2,238 & $0.97(0.86-1.09)$ & 328 & $0.68(0.61-0.77)$ \\
\hline $\begin{array}{l}\text { Congenital, familial and genetic } \\
\text { disorders }\end{array}$ & 36 & $0.18(0.13-0.25)$ & 36 & $0.21(0.15-0.29)$ & 36 & $0.28(0.20-0.39)$ & 34 & $1.06(0.25-4.41)$ & 5 & $0.70(0.27-1.80)$ \\
\hline Ear and labyrinth disorders & 226 & $0.54(0.48-0.62)$ & 226 & $0.54(0.47-0.62)$ & 226 & $0.62(0.54-0.72)$ & 196 & $0.97(0.66-1.43)$ & 52 & $1.26(0.92-1.73)$ \\
\hline Endocrine disorders & 2,863 & $6.91(6.60-7.23)$ & 2,856 & $6.69(6.38-7.02)$ & 2,863 & $3.99(3.69-4.30)$ & 2,275 & $0.88(0.80-0.97)$ & 744 & $1.60(1.46-1.75)$ \\
\hline Eye disorders & 1,194 & $0.69(0.65-0.73)$ & 1,192 & $0.68(0.64-0.72)$ & 1,194 & $0.66(0.62-0.70)$ & 1,067 & $1.00(0.83-1.21)$ & 271 & $1.21(1.05-1.39)$ \\
\hline Gastrointestinal disorders & 9,124 & $0.82(0.80-0.84)$ & 9,094 & $0.85(0.83-0.87)$ & 9,124 & $0.91(0.89-0.94)$ & 7,773 & $0.95(0.88-1.01)$ & 2,803 & $2.03(1.93-2.15)$ \\
\hline $\begin{array}{l}\text { General disorders and } \\
\text { administration site conditions }\end{array}$ & 16,449 & $0.80(0.78-0.81)$ & 16,420 & $0.76(0.74-0.77)$ & 16,449 & $0.93(0.91-0.95)$ & 15,066 & $1.04(0.98-1.11)$ & 2,894 & $0.87(0.82-0.91)$ \\
\hline Hepatobiliary disorders & 2,632 & $1.33(1.28-1.39)$ & 2,622 & 1.45 (1.39-1.51) & 2,632 & $1.32(1.26-1.38)$ & 2,149 & $0.91(0.82-1.01)$ & 426 & $0.94(0.84-1.04)$ \\
\hline Immune system disorders & 820 & $0.51(0.48-0.55)$ & 817 & $0.52(0.48-0.56)$ & 820 & $0.48(0.45-0.52)$ & 730 & $1.00(0.80-1.24)$ & 138 & $0.89(0.74-1.08)$ \\
\hline Infections and infestations & 5,795 & $0.68(0.67-0.70)$ & 5,781 & $0.73(0.71-0.76)$ & 5,795 & $0.59(0.57-0.60)$ & 5,036 & $0.97(0.89-1.05)$ & 1,063 & $1.00(0.93-1.07)$ \\
\hline $\begin{array}{l}\text { Injury, poisoning and procedural } \\
\text { complications }\end{array}$ & 6,776 & $1.20(1.17-1.23)$ & 6,767 & $1.13(1.10-1.16)$ & 6,776 & $1.09(1.06-1.12)$ & 6,185 & $1.03(0.94-1.12)$ & 797 & $0.57(0.53-0.62)$ \\
\hline Investigations & 5,147 & $0.63(0.61-0.65)$ & 5,123 & $0.70(0.68-0.72)$ & 5,147 & $0.71(0.69-0.74)$ & 4,588 & $1.00(0.91-1.10)$ & 984 & $1.02(0.94-1.10)$ \\
\hline Metabolism and nutrition disorders & 4,196 & $1.03(1.00-1.07)$ & 4,180 & $1.13(1.10-1.17)$ & 4,196 & $1.05(1.01-1.08)$ & 3,496 & $0.93(0.85-1.01)$ & 840 & $1.15(1.06-1.25)$ \\
\hline $\begin{array}{l}\text { Musculoskeletal and connective } \\
\text { tissue disorders }\end{array}$ & 3,759 & $0.89(0.86-0.92)$ & 3,751 & $0.86(0.83-0.89)$ & 3,759 & $0.97(0.93-1.00)$ & 3,332 & $0.99(0.89-1.10)$ & 539 & $0.75(0.68-0.83)$ \\
\hline
\end{tabular}


Table 2 (continued).

\begin{tabular}{|c|c|c|c|c|c|c|c|c|c|c|}
\hline \multirow[b]{2}{*}{ Toxicity of interest } & \multicolumn{2}{|c|}{$\begin{array}{c}\text { ICI vs other anticancer } \\
\text { drugs } \\
\text { (Q2/2004-Q2/2018) }\end{array}$} & \multicolumn{2}{|c|}{$\begin{array}{c}\text { ICls vs other anticancer } \\
\text { drugs } \\
\text { (Q2/2011-Q2/2018) }\end{array}$} & \multicolumn{2}{|c|}{$\begin{array}{l}\text { ICls vs monoclonal } \\
\text { antibodies } \\
\text { (Q2/2004-Q2/2018) }\end{array}$} & \multicolumn{2}{|c|}{$\begin{array}{c}\text { monotherapy vs } \\
\text { combination } \\
(n=42,156)\end{array}$} & \multicolumn{2}{|c|}{$\begin{array}{c}\text { Anti-CTLA4 monotherapy } \\
\text { vs anti-PD1/PDL1 } \\
\text { monotherapy ( } n=8,903)\end{array}$} \\
\hline & $\mathbf{N}$ & ROR (95\%Cl) & $\mathbf{N}$ & ROR $(95 \% \mathrm{Cl})$ & $\mathbf{N}$ & ROR (95\%Cl) & $\mathbf{N}$ & ROR $(95 \% \mathrm{Cl})$ & $\mathbf{N}$ & ROR (95\%Cl) \\
\hline $\begin{array}{l}\text { Neoplasms benign, malignant and } \\
\text { unspecified (incl cysts and polyps) }\end{array}$ & 8,773 & $1.85(1.81-1.90)$ & 8,762 & $1.85(1.80-1.89)$ & 8,773 & $1.67(1.63-1.72)$ & 8,064 & $1.04(0.96-1.13)$ & 1,380 & $0.78(0.73-0.83)$ \\
\hline Nervous system disorders & 5,402 & $0.71(0.69-0.73)$ & 5,386 & $0.76(0.74-0.78)$ & 5,402 & $0.76(0.73-0.78)$ & 4,817 & $1.00(0.91-1.10)$ & 1,088 & $1.08(1.00-1.16)$ \\
\hline $\begin{array}{l}\text { Pregnancy, puerperium and perinatal } \\
\text { conditions }\end{array}$ & 50 & $0.29(0.22-0.38)$ & 50 & $0.31(0.23-0.40)$ & 50 & $0.32(0.24-0.43)$ & 27 & $0.61(0.35-1.06)$ & 13 & $2.28(1.07-4.86)$ \\
\hline Product issues & 51 & $0.23(0.17-0.30)$ & 51 & $0.22(0.17-0.29)$ & 51 & $0.27(0.20-0.36)$ & 51 & NA & 3 & NC \\
\hline Psychiatric disorders & 1,432 & $0.61(0.58-0.65)$ & 1,423 & $0.63(0.60-0.67)$ & 1,432 & $0.78(0.74-0.83)$ & 1,303 & $1.02(0.85-1.23)$ & 254 & $0.92(0.80-1.06)$ \\
\hline Renal and urinary disorders & 2,377 & $0.87(0.83-0.91)$ & 2,370 & $0.96(0.92-1.00)$ & 2,377 & $0.90(0.86-0.95)$ & 2,060 & $0.97(0.86-1.10)$ & 365 & $0.83(0.74-0.93)$ \\
\hline $\begin{array}{l}\text { Reproductive system and breast } \\
\text { disorders }\end{array}$ & 188 & $0.44(0.38-0.51)$ & 187 & $0.46(0.40-0.53)$ & 188 & $0.50(0.43-0.58)$ & 170 & $1.01(0.62-1.65)$ & 23 & $0.64(0.41-0.99)$ \\
\hline $\begin{array}{l}\text { Respiratory, thoracic and mediastinal } \\
\text { disorders }\end{array}$ & 7,240 & $1.04(1.01-1.06)$ & 7,227 & $1.15(1.12-1.18)$ & 7,240 & $0.92(0.90-0.95)$ & 6,473 & 1.00 (0.92-1.09) & 728 & $0.49(0.45-0.53)$ \\
\hline $\begin{array}{l}\text { Skin and subcutaneous tissue } \\
\text { disorders }\end{array}$ & 4,618 & $0.66(0.64-0.68)$ & 4,614 & $0.64(0.62-0.66)$ & 4,618 & $0.83(0.80-0.86)$ & 4,128 & $1.00(0.91-1.11)$ & 1,084 & $1.28(1.19-1.37)$ \\
\hline Social circumstances & 107 & $0.25(0.20-0.30)$ & 107 & $0.26(0.21-0.31)$ & 107 & $0.38(0.31-0.46)$ & 104 & $1.09(0.35-3.44)$ & 15 & $0.68(0.39-1.18)$ \\
\hline Surgical and medical procedures & 1,298 & $1.20(1.13-1.27)$ & 1,298 & $1.37(1.30-1.45)$ & 1,298 & $1.64(1.53-1.75)$ & 1,180 & $1.02(0.84-1.24)$ & 186 & $0.74(0.63-0.87)$ \\
\hline Vascular disorders & 1,845 & $0.49(0.46-0.51)$ & 1,836 & $0.56(0.53-0.58)$ & 1,845 & $0.43(0.41-0.45)$ & 1,632 & $0.99(0.86-1.15)$ & 378 & $1.10(0.98-1.24)$ \\
\hline
\end{tabular}

NC: not calculated because the number of cases was $<5$ (see methods for details).

NA: not applicable because the ROR cannot be calculated (no cases in combination regimen). 
Table 3. Disproportionality analysis in FAERS (ICls compared to other oncological agents) and literature appraisal. OoSRs: overview of systematic reviews. Top priorities are shown with a dark background.

\begin{tabular}{|c|c|c|c|c|c|c|}
\hline \multirow[b]{2}{*}{ System Organ Class } & \multirow[t]{2}{*}{ FAERS* } & \multicolumn{4}{|c|}{ Literature appraisal (OoSRs) } & \multirow[t]{2}{*}{$\begin{array}{l}\text { COMBINED } \\
\text { ASSESSMENT }\end{array}$} \\
\hline & & $\begin{array}{l}\text { Outcome investigated as for the } \\
\text { original studies }\end{array}$ & $\begin{array}{l}N . \text { of studies on } \\
\text { the outcome of } \\
\text { interest }\end{array}$ & $\begin{array}{l}\text { N. of } \\
\text { positive/neutral/ } \\
\text { negative studies }\end{array}$ & Evaluation & \\
\hline $\begin{array}{l}\text { Blood and lymphatic system } \\
\text { disorders }\end{array}$ & $x$ & $\begin{array}{l}\text { Anemia, neutropenia, leukopenia, } \\
\text { hypophosphatemia, lymphopenia, } \\
\text { thrombocytopenia }\end{array}$ & 6 & 0/0/6 & $\begin{array}{l}\text { CONSISTENT NEGATIVE } \\
\text { ASSOCIATION }\end{array}$ & LOW PRIORITY \\
\hline Cardiac disorders & $x$ & $\begin{array}{l}\text { Cardiorespiratory arrest, cardiac } \\
\text { failure, myocardial infarction, } \\
\text { stroke }\end{array}$ & 2 & $0 / 1 / 1$ & UNCERTAIN ASSOCIATION & LOW PRIORITY \\
\hline Endocrine disorders & $v$ & $\begin{array}{l}\text { Hypothyroidism, hyperthyroidism, } \\
\text { hypophysitis, adrenal insufficiency, } \\
\text { thyroiditis }\end{array}$ & 9 & $9 / 0 / 0$ & $\begin{array}{l}\text { CONSISTENT POSITIVE } \\
\text { ASSOCIATION }\end{array}$ & TOP PRIORITY \\
\hline Eye disorders & $x$ & Uveitis, dry eyes & 1 & $1 / 0 / 0$ & UNCERTAIN ASSOCIATION & LOW PRIORITY \\
\hline Gastrointestinal disorders & $x$ & Colitis, diarrhea, nausea, vomiting & 11 & $6 / 2 / 3$ & $\begin{array}{l}\text { CONSISTENT POSITIVE } \\
\text { ASSOCIATION }\end{array}$ & $\begin{array}{l}\text { INTERMEDIATE } \\
\text { PRIORITY }\end{array}$ \\
\hline $\begin{array}{l}\text { General disorders and } \\
\text { administration site } \\
\text { conditions }\end{array}$ & $x$ & Fatigue, asthenia & 7 & $0 / 3 / 4$ & $\begin{array}{l}\text { CONSISTENT NEGATIVE } \\
\text { ASSOCIATION }\end{array}$ & LOW PRIORITY \\
\hline Hepatobiliary disorders & $v$ & Increased transaminases, hepatitis & 9 & $6 / 3 / 0$ & $\begin{array}{l}\text { CONSISTENT POSITIVE } \\
\text { ASSOCIATION }\end{array}$ & TOP PRIORITY \\
\hline
\end{tabular}

${ }^{*} \mathrm{x}=$ no statistically significant disproportionality emerged in primary analysis; $\mathrm{V}=$ statistically significant disproportionality emerged in primary analysis. See table 2 for details. 
Table 3 (continued).

\begin{tabular}{|c|c|c|c|c|c|c|}
\hline \multirow{2}{*}{ System Organ Class } & \multirow[t]{2}{*}{ FAERS* } & \multicolumn{4}{|c|}{ Literature appraisal (OoSRs) } & \multirow{2}{*}{$\begin{array}{l}\text { COMBINED } \\
\text { ASSESSMENT }\end{array}$} \\
\hline & & $\begin{array}{l}\text { Outcome investigated as for the } \\
\text { original studies }\end{array}$ & $\begin{array}{l}\text { N. of studies on } \\
\text { the outcome of } \\
\text { interest }\end{array}$ & $\begin{array}{l}\text { N. of positive } \\
\text { studies }\end{array}$ & Evaluation & \\
\hline $\begin{array}{l}\text { Injury, poisoning and } \\
\text { procedural complications }\end{array}$ & v & & & & & HIGH PRIORITY \\
\hline Investigations & $x$ & Lipase increased & 1 & $0 / 1 / 0$ & UNCERTAIN ASSOCIATION & LOW PRIORITY \\
\hline $\begin{array}{l}\text { Musculoskeletal and } \\
\text { connective tissue disorders }\end{array}$ & $x$ & Arthritis, vasculitis, myositis & 1 & $0 / 0 / 1$ & UNCERTAIN ASSOCIATION & LOW PRIORITY \\
\hline $\begin{array}{l}\text { Neoplasms benign, } \\
\text { malignant and unspecified } \\
\text { (incl cysts and polyps) }\end{array}$ & $\mathrm{v}$ & & & & & HIGH PRIORITY \\
\hline $\begin{array}{l}\text { Respiratory, thoracic and } \\
\text { mediastinal disorders }\end{array}$ & $\sqrt{ }$ & $\begin{array}{l}\text { Pneumonitis, interstitial lung } \\
\text { disease }\end{array}$ & 10 & $7 / 3 / 0$ & CONSISTENT POSITIVE ASSOCIATION & TOP PRIORITY \\
\hline $\begin{array}{l}\text { Skin and subcutaneous } \\
\text { tissue disorders }\end{array}$ & $x$ & Rash, pruritus, vitiligo, dermatitis & 13 & $9 / 3 / 1$ & CONSISTENT POSITIVE ASSOCIATION & $\begin{array}{l}\text { INTERMEDIATE } \\
\text { PRIORITY }\end{array}$ \\
\hline $\begin{array}{l}\text { Surgical and medical } \\
\text { procedures }\end{array}$ & v & & & & & HIGH PRIORITY \\
\hline
\end{tabular}

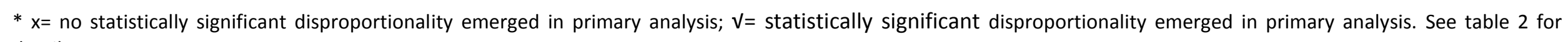
details. 
Table 4. Toxicities emerging as top and high priority: disproportionality analyses performed on the 2004Q1-2018Q2 period at PT level (signs/symptoms) and distinguishing anti-CTLA4 from anti-PD1/PDL1 agents (see methods for details). In bold: statistically-significant ROR (i.e., lower limit of the 95\%cCl of the ROR $>1$ ). Only top 10 adverse events are listed in decreasing order of frequency (ICl as a class). The sum of the number of cases for the different groups of ICI may be higher than total number of cases for the drug class because a patient may have received more than one drug (anticancer combination regimen). The full list of adverse events is provided in supplementary material 2. Largest differences in terms of frequency between anti-CTLA4 and anti-PD1/PDL1 drugs (ROR value at least 2-fold higher) are shown as gray background.

\begin{tabular}{|c|c|c|c|c|c|c|}
\hline \multirow{2}{*}{$\begin{array}{l}\text { Toxicity } \\
\text { Endocrine disorders }\end{array}$} & \multicolumn{2}{|c|}{$\begin{array}{c}\mathrm{ICl} \text { as class vs other anticancer } \\
\text { agents }\end{array}$} & \multicolumn{2}{|c|}{$\begin{array}{l}\text { Anti-CTLA4 vs other anticancer agents, } \\
\text { including anti-PD1/PDL1 drugs }\end{array}$} & \multicolumn{2}{|c|}{$\begin{array}{l}\text { Anti-PD1/PDL1 vs other anticancer agents, } \\
\text { including anti-CTLA4 drugs }\end{array}$} \\
\hline & N. cases & ROR (95\%Cl) & N. cases & ROR $(95 \% \mathrm{Cl})$ & N. cases & ROR (95\%Cl) \\
\hline Hypothyroidism & 777 & $6.36(5.85-6.93)$ & 214 & $5.92(5.15-6.82)$ & 680 & $6.87(6.29-7.50)$ \\
\hline Hypophysitis & 594 & $20.80(11.13-38.86)$ & 466 & $56.39(46.6-68.24)$ & 284 & $12.19(10.38-14.3)$ \\
\hline Adrenal insufficiency & 493 & $10.03(8.88-11.33)$ & 264 & $18.33(15.92-21.1)$ & 346 & $8.66(7.61-9.86)$ \\
\hline Hyperthyroidism & 422 & 10.09 (8.84-11.52) & 159 & $12.89(10.85-15.32)$ & 370 & $10.91(9.54-12.47)$ \\
\hline Hypopituitarism & 197 & $16.60(12.23-22.53)$ & 128 & 36.67 (28.58-47.04) & 110 & 11.40 (8.88-14.65) \\
\hline Thyroiditis & 170 & $12.91(10.13-16.46)$ & 74 & $19.05(14.59-24.88)$ & 147 & $13.76(10.86-17.44)$ \\
\hline Thyroid disorder & 151 & $4.09(3.42-4.88)$ & 43 & $3.94(2.89-5.36)$ & 127 & $4.24(3.50-5.12)$ \\
\hline Autoimmune thyroiditis & 89 & $9.60(7.24-12.74)$ & 30 & $10.95(7.42-16.17)$ & 78 & $10.37(7.78-13.82)$ \\
\hline Endocrine disorder & 65 & $12.59(8.57-18.51)$ & 47 & $30.87(21.09-45.17)$ & 29 & $6.92(4.52-10.59)$ \\
\hline Hypothalamo-pituitary disorder & 63 & $14.02(9.12-21.56)$ & 40 & $30.17(20.04-45.42)$ & 39 & $10.69(7.09-16.12)$ \\
\hline
\end{tabular}


Table 4 (continued).

\begin{tabular}{|c|c|c|c|c|c|c|}
\hline \multirow{2}{*}{$\begin{array}{l}\text { Toxicity } \\
\text { Hepatobiliary disorders }\end{array}$} & \multicolumn{2}{|c|}{$\begin{array}{c}\text { ICl as class vs other anticancer } \\
\text { agents }\end{array}$} & \multicolumn{2}{|c|}{$\begin{array}{l}\text { Anti-CTLA4 vs other anticancer agents, } \\
\text { including anti-PD1/PDL1 drugs }\end{array}$} & \multicolumn{2}{|c|}{$\begin{array}{l}\text { Anti-PD1/PDL1 vs other anticancer agents, } \\
\text { including anti-CTLA4 drugs }\end{array}$} \\
\hline & N. cases & ROR $(95 \% \mathrm{Cl})$ & N. cases & ROR (95\%Cl) & N. cases & ROR (95\%Cl) \\
\hline Hepatitis & 420 & $3.12(2.81-3.47)$ & 188 & $4.75(4.09-5.52)$ & 333 & $3.05(2.72-3.42)$ \\
\hline Hepatic function abnormal & 385 & $1.55(1.39-1.72)$ & 75 & $1.02(0.81-1.28)$ & 364 & $1.80(1.62-2.01)$ \\
\hline Autoimmune hepatitis & 373 & $14.23(11.90-17)$ & 161 & $20.85(17.34-25.07)$ & 303 & $14.24(12.04-16.84)$ \\
\hline Liver disorder & 241 & $1.18(1.04-1.35)$ & 102 & $1.70(1.39-2.07)$ & 196 & $1.19(1.03-1.37)$ \\
\hline Hepatic failure & 193 & $0.91(0.78-1.05)$ & 72 & $1.14(0.91-1.45)$ & 151 & $0.87(0.74-1.03)$ \\
\hline Hepatotoxicity & 154 & $1.04(0.88-1.22)$ & 70 & $1.59(1.26-2.02)$ & 116 & $0.96(0.80-1.16)$ \\
\hline Drug-induced liver injury & 123 & $2.37(1.96-2.86)$ & 47 & $3.06(2.28-4.10)$ & 102 & $2.42(1.97-2.96)$ \\
\hline Hepatocellular injury & 117 & $1.45(1.20-1.75)$ & 42 & $1.76(1.30-2.40)$ & 97 & $1.48(1.21-1.82)$ \\
\hline Cholestasis & 116 & $1.41(1.17-1.70)$ & 36 & $1.48(1.06-2.06)$ & 101 & $1.51(1.24-1.85)$ \\
\hline Cholangitis & 110 & $2.11(1.73-2.57)$ & 11 & $0.71(0.39-1.29)$ & 106 & $2.51(2.05-3.07)$ \\
\hline
\end{tabular}


Table 4 (continued).

\begin{tabular}{|c|c|c|c|c|c|c|}
\hline \multirow{2}{*}{$\begin{array}{l}\text { Toxicity } \\
\text { Respiratory disorders }\end{array}$} & \multicolumn{2}{|c|}{$\begin{array}{c}\text { ICl as class vs other anticancer } \\
\text { agents }\end{array}$} & \multicolumn{2}{|c|}{$\begin{array}{l}\text { Anti-CTLA4 vs other anticancer agents, } \\
\text { including anti-PD1/PDL1 drugs }\end{array}$} & \multicolumn{2}{|c|}{$\begin{array}{l}\text { Anti-PD1/PDL1 vs other anticancer agents, } \\
\text { including anti-CTLA4 drugs }\end{array}$} \\
\hline & N. cases & ROR $(95 \% \mathrm{Cl})$ & N. cases & ROR (95\%Cl) & N. cases & ROR (95\%Cl) \\
\hline Dyspnoea & 1,614 & $0.91(0.87-0.96)$ & 411 & $0.78(0.71-0.86)$ & 1,423 & $0.99(0.94-1.05)$ \\
\hline Pneumonitis & 1,289 & $4.06(3.82-4.32)$ & 304 & $3.22(2.87-3.62)$ & 1,196 & $4.66(4.38-4.97)$ \\
\hline Interstitial lung disease & 794 & $1.63(1.52-1.75)$ & 74 & $0.51(0.40-0.64)$ & 761 & $1.93(1.79-2.08)$ \\
\hline Pleural effusion & 656 & $0.97(0.90-1.05)$ & 136 & $0.68(0.57-0.81)$ & 598 & $1.09(1.01-1.19)$ \\
\hline Cough & 646 & $0.88(0.82-0.96)$ & 128 & $0.59(0.49-0.70)$ & 580 & $0.98(0.90-1.06)$ \\
\hline Respiratory failure & 537 & $1.08(0.99-1.18)$ & 103 & $0.70(0.58-0.85)$ & 482 & $1.20(1.09-1.31)$ \\
\hline Pulmonary embolism & 413 & $0.80(0.72-0.88)$ & 131 & $0.86(0.72-1.02)$ & 325 & $0.77(0.69-0.87)$ \\
\hline Lung disorder & 330 & $1.28(1.14-1.43)$ & 37 & $0.48(0.35-0.67)$ & 311 & $1.49(1.33-1.67)$ \\
\hline Haemoptysis & 256 & $1.54(1.36-1.75)$ & 29 & $0.59(0.41-0.85)$ & 241 & $1.79(1.57-2.04)$ \\
\hline Hypoxia & 217 & $0.96(0.84-1.10)$ & 61 & $0.91(0.71-1.18)$ & 198 & $1.08(0.94-1.25)$ \\
\hline
\end{tabular}


Table 4 (continued).

\begin{tabular}{|c|c|c|c|c|c|c|}
\hline \multirow{2}{*}{$\begin{array}{l}\text { Toxicity } \\
\text { Neoplasms benign, malignant } \\
\text { and unspecified (incl cysts and } \\
\text { polyps) }\end{array}$} & \multicolumn{2}{|c|}{$\begin{array}{c}\mathrm{ICl} \text { as class vs other anticancer } \\
\text { agents }\end{array}$} & \multicolumn{2}{|c|}{$\begin{array}{l}\text { Anti-CTLA4 vs other anticancer agents, } \\
\text { including anti-PD1/PDL1 drugs }\end{array}$} & \multicolumn{2}{|c|}{$\begin{array}{l}\text { Anti-PD1/PDL1 vs other anticancer agents, } \\
\text { including anti-CTLA4 drugs }\end{array}$} \\
\hline & N. cases & ROR (95\%Cl) & N. cases & ROR $(95 \% \mathrm{Cl})$ & N. cases & ROR $(95 \% \mathrm{Cl})$ \\
\hline Malignant neoplasm progression & 6,691 & $5.94(5.77-6.12)$ & 1,416 & $4.06(3.84-4.3)$ & 5,806 & $6.42(6.23-6.63)$ \\
\hline $\begin{array}{l}\text { Metastases to central nervous } \\
\text { system }\end{array}$ & 343 & $2.03(1.81-2.27)$ & 132 & $2.65(2.22-3.15)$ & 252 & $1.83(1.61-2.09)$ \\
\hline Neoplasm malignant & 280 & $1.11(0.98-1.25)$ & 229 & $3.10(2.72-3.55)$ & 53 & $0.26(0.20-0.34)$ \\
\hline Neoplasm progression & 140 & $0.36(0.31-0.43)$ & 45 & $0.40(0.30-0.53)$ & 102 & $0.33(0.27-0.40)$ \\
\hline Metastases to bone & 105 & $0.85(0.70-1.04)$ & 21 & $0.58(0.37-0.89)$ & 98 & $0.98(0.80-1.20)$ \\
\hline Metastases to liver & 94 & $0.52(0.42-0.63)$ & 39 & $0.72(0.53-0.99)$ & 74 & $0.50(0.40-0.63)$ \\
\hline Tumour pseudoprogression & 94 & $17.42(10.64-28.52)$ & 8 & $5.01(2.44-10.28)$ & 94 & 21.47 (13.11-35.15) \\
\hline Metastases to lung & 81 & $0.60(0.48-0.75)$ & 36 & $0.91(0.65-1.26)$ & 64 & $0.59(0.46-0.75)$ \\
\hline Neoplasm & 79 & $0.91(0.73-1.15)$ & 28 & $1.10(0.76-1.59)$ & 60 & $0.86(0.66-1.11)$ \\
\hline Tumour haemorrhage & 68 & $1.70(1.33-2.18)$ & 22 & $1.86(1.22-2.85)$ & 53 & $1.64(1.24-2.16)$ \\
\hline
\end{tabular}


Table 4 (continued).

\begin{tabular}{|c|c|c|c|c|c|c|}
\hline \multirow{2}{*}{$\begin{array}{l}\text { Toxicity } \\
\begin{array}{l}\text { Injury, poisoning and procedural } \\
\text { complications }\end{array}\end{array}$} & \multicolumn{2}{|c|}{$\begin{array}{c}\mathrm{ICl} \text { as class vs other anticancer } \\
\text { agents }\end{array}$} & \multicolumn{2}{|c|}{$\begin{array}{l}\text { Anti-CTLA4 vs other anticancer agents, } \\
\text { including anti-PD1/PDL1 drugs }\end{array}$} & \multicolumn{2}{|c|}{$\begin{array}{l}\text { Anti-PD1/PDL1 vs other anticancer } \\
\text { agents, including anti-CTLA4 drugs }\end{array}$} \\
\hline & N. cases & ROR $(95 \% \mathrm{Cl})$ & N. cases & ROR (95\%Cl) & N. cases & ROR $(95 \% \mathrm{Cl})$ \\
\hline $\begin{array}{l}\text { Product use in unapproved } \\
\text { indication }\end{array}$ & 1,734 & $6.29(5.94-6.66)$ & 312 & $3.77(3.36-4.23)$ & 1,687 & $7.60(7.17-8.04)$ \\
\hline Product use issue & 1,365 & $3.99(3.76-4.23)$ & 69 & $0.67(0.52-0.84)$ & 1,342 & $4.86(4.58-5.16)$ \\
\hline Off label use & 1,183 & $0.88(0.83-0.93)$ & 266 & $0.67(0.59-0.75)$ & 1,015 & $0.93(0.88-0.99)$ \\
\hline Infusion related reaction & 365 & $1.05(0.94-1.16)$ & 79 & $0.77(0.61-0.96)$ & 315 & $1.11(0.99-1.25)$ \\
\hline Fall & 320 & $0.6(0.54-0.67)$ & 78 & $0.49(0.39-0.62)$ & 263 & $0.61(0.54-0.69)$ \\
\hline Prescribed overdose & 262 & $14.64(11.75-18.24)$ & 232 & 44.34 (35.99-54.63) & 51 & $3.50(2.60-4.70)$ \\
\hline Incorrect product storage & 241 & $6.25(5.38-7.27)$ & 50 & $4.38(3.29-5.84)$ & 201 & $6.42(5.48-7.54)$ \\
\hline $\begin{array}{l}\text { Inappropriate schedule of drug } \\
\text { administration }\end{array}$ & 180 & $1.67(1.43-1.94)$ & 17 & $0.53(0.33-0.86)$ & 177 & $2.02(1.73-2.36)$ \\
\hline Toxicity to various agents & 174 & $0.41(0.35-0.47)$ & 79 & $0.63(0.5-0.78)$ & 114 & $0.33(0.27-0.4)$ \\
\hline Drug dose omission & 137 & $0.49(0.41-0.58)$ & 18 & $0.22(0.14-0.34)$ & 120 & $0.53(0.44-0.63)$ \\
\hline
\end{tabular}


Table 4 (continued).

\begin{tabular}{|c|c|c|c|c|c|c|}
\hline \multirow{2}{*}{$\begin{array}{l}\text { Toxicity } \\
\text { Surgical and medical procedures }\end{array}$} & \multicolumn{2}{|c|}{$\begin{array}{c}\mathrm{ICl} \text { as class vs other anticancer } \\
\text { agents }\end{array}$} & \multicolumn{2}{|c|}{$\begin{array}{l}\text { Anti-CTLA4 vs other anticancer agents, } \\
\text { including anti-PD1/PDL1 drugs }\end{array}$} & \multicolumn{2}{|c|}{$\begin{array}{l}\text { Anti-PD1/PDL1 vs other anticancer } \\
\text { agents, including anti-CTLA4 drugs }\end{array}$} \\
\hline & N. cases & ROR $(95 \% \mathrm{Cl})$ & N. cases & ROR $(95 \% \mathrm{Cl})$ & N. cases & ROR $(95 \% \mathrm{Cl})$ \\
\hline Transfusion & 172 & $5.19(4.37-6.16)$ & 37 & $3.77(2.71-5.25)$ & 155 & $5.76(4.82-6.89)$ \\
\hline Hospitalisation & 139 & $0.82(0.69-0.97)$ & 56 & $1.12(0.86-1.45)$ & 103 & $0.75(0.61-0.91)$ \\
\hline Hospice care & 99 & $3.10(2.50-3.83)$ & 16 & $1.69(1.03-2.78)$ & 93 & $3.59(2.88-4.46)$ \\
\hline Surgery & 98 & $1.46(1.19-1.79)$ & 21 & $1.05(0.69-1.62)$ & 82 & $1.50(1.2-1.88)$ \\
\hline Therapy cessation & 55 & $0.95(0.73-1.25)$ & 22 & $1.29(0.85-1.97)$ & 33 & $0.71(0.50-1.00)$ \\
\hline Packed red blood cell transfusion & 47 & $7.62(5.32-10.91)$ & 10 & $5.48(2.88-10.46)$ & 43 & $8.59(5.96-12.39)$ \\
\hline Platelet transfusion & 33 & $4.31(2.94-6.33)$ & 5 & $2.21(0.91-5.38)$ & 31 & 4.99 (3.37-7.39) \\
\hline Dialysis & 26 & $0.54(0.36-0.79)$ & 3 & NC & 23 & $0.58(0.39-0.88)$ \\
\hline Thoracic cavity drainage & 26 & 7.15 (4.45-11.49) & 1 & NC & 25 & $8.47(5.25-13.68)$ \\
\hline Cardiac pacemaker insertion & 23 & $2.88(1.85-4.47)$ & 6 & $2.54(1.12-5.74)$ & 21 & $3.24(2.05-5.12)$ \\
\hline
\end{tabular}

NC: not calculated because the number of cases was $<5$ (see methods for details). 


\section{References}

1. Clarke JM, George DJ, Lisi S, Salama AKS. Immune Checkpoint Blockade: The New Frontier in Cancer Treatment. Target Oncol.2018;13:1-20

2. Martin-Liberal J, Hierro C, Ochoa de OM, Rodon J. Immuno-Oncology: The Third Paradigm in Early Drug Development. Target Oncol.2017;12:125-38

3. Hoos A. Development of immuno-oncology drugs - from CTLA4 to PD1 to the next generations. Nat Rev Drug Discov.2016;15:235-47

4. Friedman CF, Proverbs-Singh TA, Postow MA. Treatment of the Immune-Related Adverse Effects of Immune Checkpoint Inhibitors: A Review. JAMA Oncol.2016;2:1346-53

5. Johnson DB, Balko JM, Compton ML, Chalkias S, Gorham J, Xu Y, Hicks M, Puzanov I, Alexander MR, Bloomer TL, Becker JR, Slosky DA, Phillips EJ, Pilkinton MA, Craig-Owens L, Kola N, Plautz G, Reshef DS, Deutsch JS, Deering RP, Olenchock BA, Lichtman AH, Roden DM, Seidman CE, Koralnik IJ, Seidman JG, Hoffman RD, Taube JM, Diaz LA, Jr., Anders RA, Sosman JA, Moslehi JJ. Fulminant Myocarditis with Combination Immune Checkpoint Blockade. N Engl J Med.2016;375:1749-55

6. Postow MA, Sidlow R, Hellmann MD. Immune-Related Adverse Events Associated with Immune Checkpoint Blockade. N Engl J Med.2018;378:158-68

7. Brahmer JR, Lacchetti C, Schneider BJ, Atkins MB, Brassil KJ, Caterino JM, Chau I, Ernstoff MS, Gardner JM, Ginex P, Hallmeyer S, Holter CJ, Leighl NB, Mammen JS, McDermott DF, Naing A, Nastoupil LJ, Phillips T, Porter LD, Puzanov I, Reichner CA, Santomasso BD, Seigel C, Spira A, Suarez-Almazor ME, Wang Y, Weber JS, Wolchok JD, Thompson JA. Management of Immune-Related Adverse Events in Patients Treated With Immune Checkpoint Inhibitor Therapy: American Society of Clinical Oncology Clinical Practice Guideline. J Clin Oncol.2018;36:1714-68

8. Martins F, Sykiotis GP, Maillard M, Fraga M, Ribi C, Kuntzer T, Michielin O, Peters S, Coukos G, Spertini F, Thompson JA, Obeid $M$. New therapeutic perspectives to manage refractory immune checkpoint-related toxicities. Lancet Oncol.2019;20:e54-e64

9. Boutros C, Tarhini A, Routier E, Lambotte O, Ladurie FL, Carbonnel F, Izzeddine H, Marabelle A, Champiat S, Berdelou A, Lanoy E, Texier M, Libenciuc C, Eggermont AM, Soria JC, Mateus C, Robert C. Safety profiles of antiCTLA-4 and anti-PD-1 antibodies alone and in combination. Nat Rev Clin Oncol.2016;13:473-86

10. Raschi E, Diemberger I, Cosmi B, De Ponti F. ESC position paper on cardiovascular toxicity of cancer treatments: challenges and expectations. Intern Emerg Med.2018;13:1-9

11. Baxi S, Yang A, Gennarelli RL, Khan N, Wang Z, Boyce L, Korenstein D. Immune-related adverse events for antiPD-1 and anti-PD-L1 drugs: systematic review and meta-analysis. BMJ.2018;360:k793

12. Abdel-Wahab N, Shah M, Lopez-Olivo MA, Suarez-Almazor ME. Use of Immune Checkpoint Inhibitors in the Treatment of Patients With Cancer and Preexisting Autoimmune Disease: A Systematic Review. Ann Intern Med.2018;168:121-30

13. Moslehi JJ, Salem JE, Sosman JA, Lebrun-Vignes B, Johnson DB. Increased reporting of fatal immune checkpoint inhibitor-associated myocarditis. Lancet.2018;391:933

14. Ferreira M, Pichon E, Carmier D, Bouquet E, Pageot C, Bejan-Angoulvant T, Campana M, Vermes E, MarchandAdam S. Coronary Toxicities of Anti-PD-1 and Anti-PD-L1 Immunotherapies: a Case Report and Review of the Literature and International Registries. Target Oncol.2018;13:509-515

15. Centanni M, Moes DJAR, Troconiz IF, Ciccolini J, van Hasselt JGC. Clinical Pharmacokinetics and Pharmacodynamics of Immune Checkpoint Inhibitors. Clin Pharmacokinet.2019; Feb 28. doi: 10.1007/s40262019-00748-2

16. Sakaeda T, Tamon A, Kadoyama K, Okuno Y. Data mining of the public version of the FDA Adverse Event Reporting System. Int J Med Sci.2013;10:796-803

17. Giezen TJ, Mantel-Teeuwisse AK, Meyboom RH, Straus SM, Leufkens HG, Egberts TC. Mapping the safety profile of biologicals: a disproportionality analysis using the WHO adverse drug reaction database, VigiBase. Drug Saf.2010;33:865-78 
18. Cutroneo PM, Isgro V, Russo A, lentile V, Sottosanti L, Pimpinella G, Conforti A, Moretti U, Caputi AP, Trifiro G. Safety profile of biological medicines as compared with non-biologicals: an analysis of the italian spontaneous reporting system database. Drug Saf.2014;37:961-70

19. Gouverneur A, Claraz P, Rousset M, Arnaud M, Fourrier-Reglat A, Pariente A, Aparicio T, Miremont-Salame G, Noize P. Comparative Safety of Targeted Therapies for Metastatic Colorectal Cancer between Elderly and Younger Patients: a Study Using the International Pharmacovigilance Database. Target Oncol.2017;12:805-14

20. Araujo AGS, Borba HHL, Tonin FS, Lenzi L, Venson R, Pontarolo R, Wiens A. Safety of Biologics Approved for the Treatment of Rheumatoid Arthritis and Other Autoimmune Diseases: A Disproportionality Analysis from the FDA Adverse Event Reporting System (FAERS). BioDrugs.2018;32:377-90

21. Raschi E, Poluzzi E, Salvo F, Pariente A, De Ponti F, Marchesini G, Moretti U. Pharmacovigilance of sodium-glucose co-transporter-2 inhibitors: What a clinician should know on disproportionality analysis of spontaneous reporting systems. Nutr Metab Cardiovasc Dis.2018;28:533-542

22. Fukazawa C, Hinomura $Y$, Kaneko M, Narukawa M. Significance of data mining in routine signal detection: Analysis based on the safety signals identified by the FDA. Pharmacoepidemiol Drug Saf.2018;27:1402-8

23. Harpaz R, DuMouchel W, LePendu P, Bauer-Mehren A, Ryan P, Shah NH. Performance of pharmacovigilance signal-detection algorithms for the FDA adverse event reporting system. Clin Pharmacol Ther.2013;93:539-46

24. Poluzzi E, Raschi E, Piccinni C, De Ponti F. Data Mining Techniques in Pharmacovigilance: Analysis of the Publicly Accessible FDA Adverse Event Reporting System (AERS). In: Karahoca A, editor. Data mining applications in engineering and medicine. Croatia: InTech; 2012. p. 265-302

25. Bate A, Evans SJ. Quantitative signal detection using spontaneous ADR reporting. Pharmacoepidemiol Drug Saf.2009;18:427-36

26. Tuccori M, Montagnani S, Capogrosso-Sansone A, Mantarro S, Antonioli L, Fornai M, Blandizzi C. Adverse reactions to oncologic drugs: spontaneous reporting and signal detection. Expert Rev Clin Pharmacol.2015;8:6175

27. Slattery J, Alvarez Y, Hidalgo A. Choosing thresholds for statistical signal detection with the proportional reporting ratio. Drug Saf.2013;36:687-92

28. Hauben M, Hung E, Wood J, Soitkar A, Reshef D. The impact of database restriction on pharmacovigilance signal detection of selected cancer therapies. Ther Adv Drug Saf.2017;8:145-56

29. Bragge P, Clavisi O, Turner T, Tavender E, Collie A, Gruen RL. The Global Evidence Mapping Initiative: scoping research in broad topic areas. BMC Med Res Methodol.2011;11:92

30. Baraibar I, Melero I, Ponz-Sarvise M, Castanon E. Safety and Tolerability of Immune Checkpoint Inhibitors (PD-1 and PD-L1) in Cancer. Drug Saf.2019 Jan 16. doi: 10.1007/s40264-018-0774-8

31. Khoja L, Day D, Wei-Wu CT, Siu LL, Hansen AR. Tumour- and class-specific patterns of immune-related adverse events of immune checkpoint inhibitors: a systematic review. Ann Oncol.2017;28:2377-85

32. Xu C, Chen YP, Du XJ, Liu JQ, Huang CL, Chen L, Zhou GQ, Li WF, Mao YP, Hsu C, Liu Q, Lin AH, Tang LL, Sun Y, Ma J. Comparative safety of immune checkpoint inhibitors in cancer: systematic review and network meta-analysis. BMJ.2018;363:k4226

33. Ali AK, Watson DE. Pharmacovigilance Assessment of Immune-Mediated Reactions Reported for Checkpoint Inhibitor Cancer Immunotherapies. Pharmacotherapy.2017;37:1383-90

34. Wang DY, Salem JE, Cohen JV, Chandra S, Menzer C, Ye F, Zhao S, Das S, Beckermann KE, Ha L, Rathmell WK, Ancell KK, Balko JM, Bowman C, Davis EJ, Chism DD, Horn L, Long GV, Carlino MS, Lebrun-Vignes B, Eroglu Z, Hassel JC, Menzies AM, Sosman JA, Sullivan RJ, Moslehi JJ, Johnson DB. Fatal Toxic Effects Associated With Immune Checkpoint Inhibitors: A Systematic Review and Meta-analysis. JAMA Oncol.2018;4:1721-8

35. Ji HH, Tang XW, Dong Z, Song L, Jia YT. Adverse Event Profiles of Anti-CTLA-4 and Anti-PD-1 Monoclonal Antibodies Alone or in Combination: Analysis of Spontaneous Reports Submitted to FAERS. Clin Drug Investig.2019 Jan 23. doi: 10.1007/s40261-018-0735-0

36. Macia-Martinez MA, de Abajo FJ, Roberts G, Slattery J, Thakrar B, Wisniewski AF. An Empirical Approach to Explore the Relationship Between Measures of Disproportionate Reporting and Relative Risks from Analytical Studies. Drug Saf.2016;39:29-43 
37. Sosa A, Lopez CE, Simon OC, Karachaliou N, Rosell R. Clinical assessment of immune-related adverse events. Ther Adv Med Oncol.2018;10:1758835918764628

38. Suzman DL, Pelosof L, Rosenberg A, Avigan MI. Hepatotoxicity of immune checkpoint inhibitors: An evolving picture of risk associated with a vital class of immunotherapy agents. Liver Int.2018;38:976-87

39. De Martin E., Michot JM, Papouin B, Champiat S, Mateus C, Lambotte O, Roche B, Antonini TM, Coilly A, Laghouati S, Robert C, Marabelle A, Guettier C, Samuel D. Characterization of liver injury induced by cancer immunotherapy using immune checkpoint inhibitors. J Hepatol.2018;68:1181-1190

40. Wang W, Lie P, Guo M, He J. Risk of hepatotoxicity in cancer patients treated with immune checkpoint inhibitors: A systematic review and meta-analysis of published data. Int J Cancer.2017;141:1018-28

41. Gelsomino F, Vitale G, D'Errico A, Bertuzzi C, Andreone P, Ardizzoni A. Nivolumab-induced cholangitic liver disease: a novel form of serious liver injury. Ann Oncol.2017;28:671-2

42. Gelsomino F, Vitale G, Ardizzoni A. Immune-mediated cholangitis: is it always nivolumab's fault? Cancer Immunol Immunother.2018;67:1325-1327

43. Kawakami H, Tanizaki J, Tanaka K, Haratani K, Hayashi H, Takeda M, Kamata K, Takenaka M, Kimura M, Chikugo T, Sato T, Kudo M, Ito A, Nakagawa K. Imaging and clinicopathological features of nivolumab-related cholangitis in patients with non-small cell lung cancer. Invest New Drugs.2017;35:529-36

44. Kashima J, Okuma Y, Shimizuguchi R, Chiba K. Bile duct obstruction in a patient treated with nivolumab as second-line chemotherapy for advanced non-small-cell lung cancer: a case report. Cancer Immunol Immunother.2018;67:61-5

45. Gelsomino F, Vitale G, Ardizzoni A. A case of nivolumab-related cholangitis and literature review: how to look for the right tools for a correct diagnosis of this rare immune-related adverse event. Invest New Drugs.2018;36:1446

46. Ogawa K, Kamimura K, Terai S. Anti-Programmed Cell Death-1 Immunotherapy-Related Secondary Sclerosing Cholangitis. Hepatology.2018;69:914-916

47. Noda-Narita S, Mizuno S, Noguchi S, Watanabe K, Nakai Y, Koike K, Kage H, Nagase T. Development of mild druginduced sclerosing cholangitis after discontinuation of nivolumab. Eur J Cancer.2019;107:93-6

48. Bonkovsky HL, Kleiner DE, Gu J, Odin JA, Russo MW, Navarro VM, Fontana RJ, Ghabril MS, Barnhart H, Hoofnagle $\mathrm{JH}$. Clinical presentations and outcomes of bile duct loss caused by drugs and herbal and dietary supplements. Hepatology.2017;65:1267-77

49. Misu T, Kortepeter CM, Munoz MA, Wu E, Dal Pan GJ. An Evaluation of "Drug Ineffective" Postmarketing Reports in Drug Safety Surveillance. Drugs Real World Outcomes.2018;

50. Juhlin K, Karimi G, Ander M, Camilli S, Dheda M, Har TS, Isahak R, Lee SJ, Vaughan S, Caduff P, Noren GN. Using VigiBase to Identify Substandard Medicines: Detection Capacity and Key Prerequisites. Drug Saf.2015;38:373-82

51. Trippe ZA, Brendani B, Meier C, Lewis D. Identification of Substandard Medicines via Disproportionality Analysis of Individual Case Safety Reports. Drug Saf.2017;40:293-303

52. Inacio $\mathrm{P}$, Cavaco $\mathrm{A}$, Airaksinen $\mathrm{M}$. The value of patient reporting to the pharmacovigilance system: a systematic review. Br J Clin Pharmacol.2017;83:227-46

53. Champiat S, Dercle L, Ammari S, Massard C, Hollebecque A, Postel-Vinay S, Chaput N, Eggermont A, Marabelle A, Soria JC, Ferte C. Hyperprogressive Disease Is a New Pattern of Progression in Cancer Patients Treated by AntiPD-1/PD-L1. Clin Cancer Res.2017;23:1920-8

54. Chiou VL, Burotto M. Pseudoprogression and Immune-Related Response in Solid Tumors. J Clin Oncol.2015;33:3541-3

55. Sato K, Akamatsu H, Murakami E, Sasaki S, Kanai K, Hayata A, Tokudome N, Akamatsu K, Koh Y, Ueda H, Nakanishi M, Yamamoto $\mathrm{N}$. Correlation between immune-related adverse events and efficacy in non-small cell lung cancer treated with nivolumab. Lung Cancer.2018;115:71-4

56. Haratani K, Hayashi H, Chiba Y, Kudo K, Yonesaka K, Kato R, Kaneda H, Hasegawa Y, Tanaka K, Takeda M, Nakagawa K. Association of Immune-Related Adverse Events With Nivolumab Efficacy in Non-Small-Cell Lung Cancer. JAMA Oncol.2018;4:374-8 
57. Teraoka S, Fujimoto D, Morimoto T, Kawachi H, Ito M, Sato Y, Nagata K, Nakagawa A, Otsuka K, Uehara K, Imai Y, Ishida K, Fukuoka J, Tomii K. Early Immune-Related Adverse Events and Association with Outcome in Advanced Non-Small Cell Lung Cancer Patients Treated with Nivolumab: A Prospective Cohort Study. J Thorac Oncol.2017;12:1798-805

58. Michel C, Scosyrev E, Petrin M, Schmouder R. Can Disproportionality Analysis of Post-marketing Case Reports be Used for Comparison of Drug Safety Profiles? Clin Drug Investig.2017;37:415-22

59. Oshima Y, Tanimoto T, Yuji K, Tojo A. EGFR-TKI-Associated Interstitial Pneumonitis in Nivolumab-Treated Patients With Non-Small Cell Lung Cancer. JAMA Oncol.2018;4:1112-1115

60. Salem JE, Manouchehri A, Moey M, Lebrun-Vignes B, Bastarache L, Pariente A, Gobert A, Spano JP, Balko JM, Bonaca MP, Roden DM, Johnson DB, Moslehi JJ. Cardiovascular toxicities associated with immune checkpoint inhibitors: an observational, retrospective, pharmacovigilance study. Lancet Oncol.2018;19:1579-89

61. Arora A, Jalali RK, Vohora D. Relevance of the Weber effect in contemporary pharmacovigilance of oncology drugs. Ther Clin Risk Manag.2017;13:1195-203

62. Trifiro G, Sultana J, Bate A. From Big Data to Smart Data for Pharmacovigilance: The Role of Healthcare Databases and Other Emerging Sources. Drug Saf.2018;41:143-9

63. Kibbelaar RE, Oortgiesen BE, van der Wal-Oost AM, Boslooper K, Coebergh JW, Veeger NJGM, Joosten P, Storm $\mathrm{H}$, van Roon EN, Hoogendoorn M. Bridging the gap between the randomised clinical trial world and the real world by combination of population-based registry and electronic health record data: A case study in haematooncology. Eur J Cancer.2017;86:178-85 
Flow Chart to compare FAERS analysis with Literature assessment. ICl: immune checkpoint inhibitor; SRs: systematic reviews.

- Primary Suspect or Secondary Suspect (see text for details), RCTs: randomized controlled trials.

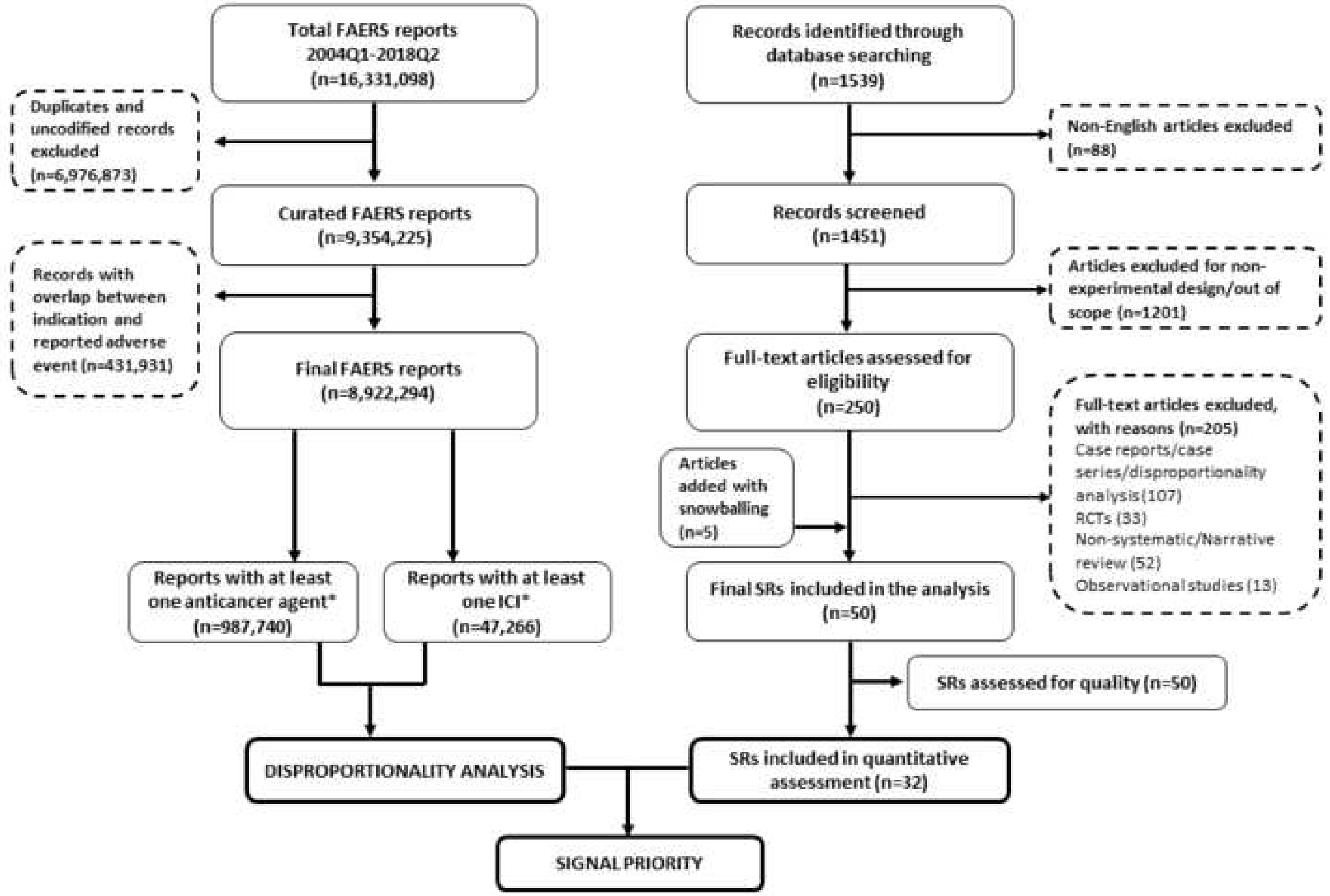


Ipilimumab (Mar 2011)

sew

\section{Pembrolizumab (sept 2014)}

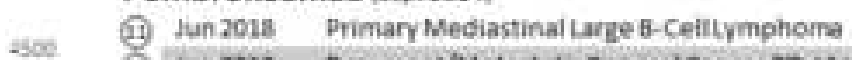

(6i) Junzia Fiecurtent/MetastaticCervicalCancerPD-L1+

(i) Sep 2017 Advanced/Metastatic Goutnc or Gastroesophageal PD-L1.

(6) May 2017 souid Tumorwith SpesificGenetic Feature

ando

(1) May 2017 Lecally Advanced/Metastatic Urothelial Carcinoms

(6) May 2017 Metastatic Nonsqumeus NsCCC irmspective of POUL

3500

(5) Mar 2017 Clessical Hodgkin LymphomachL

(9) Oet 2016 Metastatienscic

(i) Aup 2016 Fecurrunt/MetastaticHeais/Neck Squanous Ceflil Carinang

(3) Dec 2015 Patientswith Advanced Melanonn

3000

(5) Sep2014 AdvancedMelanema

Nivolumab (Dec 2014)

7. Aug 2017 Metastatic Colorectal Cancer

5. Feb2017 Urothetial Carcinoma

5 Nov 2016 Head NeckCancer

4 May 2018 Hodking Lymphoma

i] Nov2015 RenalCeliCarcinems

15 Ott2015 Advancediuncancer

13. Mar 2015 Lun Cancer

0. Dec2014 Advanced Melanoma
Atezolizumab (0Any 2016)

$\begin{array}{ll}\text { A. Apr } 2017 & \text { Advanced Bladder Cancer } \\ \text { of Oct 2016 } & \text { Specitic Type of Metastatictung Cancer: } \\ \text { \& May 2016 } & \text { Urothelial Carcinoma }\end{array}$

\section{Avelumab imar 2017 ?}

1) Mry 2017 UrotheliatCarcinoma

5) Mv 2017 MetartaticMerkefCellCarcinoma

\section{Durvalumab eMvi 2015}

(1) Fob201a Unresectablestage ilinscic

0) Mavios Advanced Hiadder Cancer

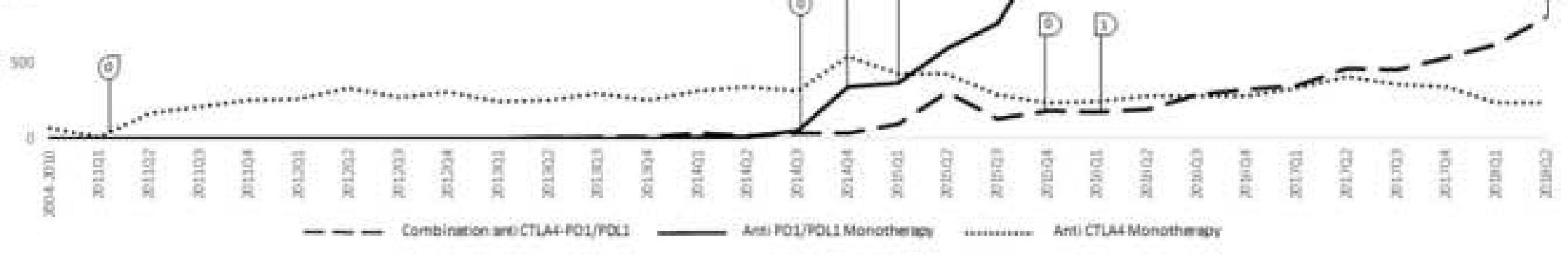

Ipilimumab + Nivolumab joce 2015

(a) Oet 2015 BRAFV 600 Wr Molanoma

3) $2 a n 2016$ Uniesectable Melanoma

2. Apr 2014 Advanced Aenal Celi Carcinoma

(B) Junzols Mutastatic Colorectal Cäncer

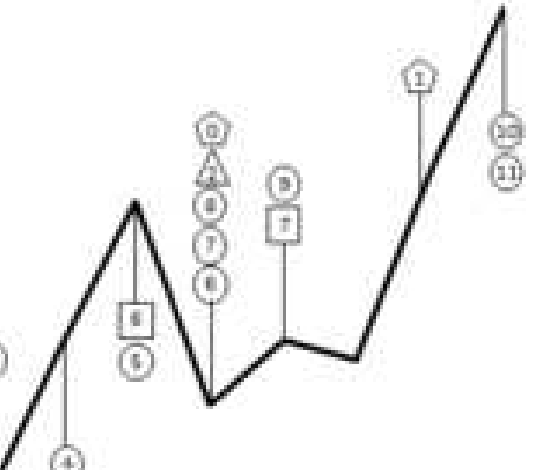


Endocrine disorders

Hepatobiliary disorders

$(\mathrm{N}=2,863$ )

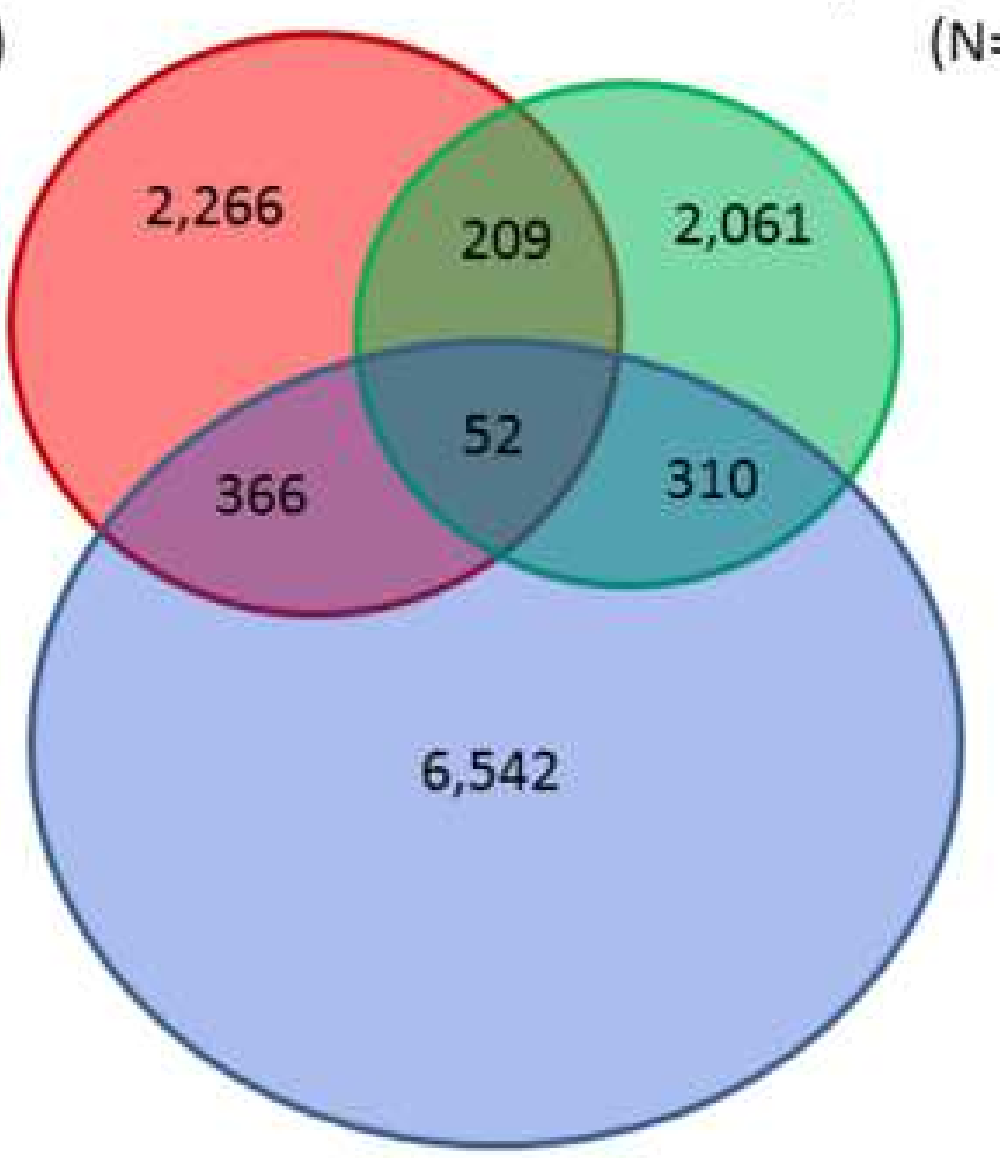

Respiratory, thoracic and mediastinal disorders $(\mathrm{N}=7,242)$ 